\title{
THE SEISMIC RESPONSE OF ELEVATED LIQUID STORAGE TANKS ISOLATED BY LEAD-RUBBER BEARINGS
}

\author{
M.K. Shrimali ${ }^{1}$ and R.S. Jangid ${ }^{2}$
}

\begin{abstract}
The seismic response of elevated liquid storage tanks isolated by the lead-rubber bearing is investigated under real earthquake ground motion. Two types of isolated tank models are considered in which the bearings are placed at the base and top of the tower structure. The tank liquid is modelled as lumped masses referred as convective mass, impulsive mass and rigid mass. The corresponding stiffness associated with these lumped masses has been worked out using the properties of the tank wall and liquid mass based on simple single-degree-of-freedom concepts. The mass of the tower structure is lumped equally at top and bottom. The assembled equations of motion are solved by Newmark's step-by-step method with iteration. The seismic response of two types of tanks, namely slender and broad tanks is obtained and a parametric study is carried out to study the effects of important system parameters on the effectiveness of seismic isolation. The various important parameters considered are the tank aspect ratio, the time period of the tower structure, damping and the time period of the isolation system. It has been observed that the earthquake response of the isolated tank is reduced significantly. Further, it is observed that the isolation is more effective for the tank with a stiff tower structure in comparison to flexible towers. In addition, a simplified analysis is also presented to evaluate the response of the elevated tanks using a two-degrees-of-freedom model and two single degree-of-freedom models. It is observed that the proposed methods predict accurately the seismic response of elevated liquid storage tanks with less computational efforts.
\end{abstract}

Keywords: elevated liquid storage tanks, lead-rubber bearings, base isolation, earthquake, and system parameters.

\section{INTRODUCTION}

The tanks are lifeline structures, which are connected for public use and also are strategically very important structures, since they have vital uses in industry and nuclear power plants. The elevated liquid storage tanks are horizontally flexible but attract considerable attention to safe guard against possible devastating earthquake due to failure of the tanks [1]. The tanks are manufactured for a wide range of capacities from small to very large. The earthquake motion excites the liquid contained in the tank. Part of the liquid moves independently of the tank wall motion, which is termed sloshing, while another part of the liquid which moves in unison with the rigid tank wall is known as impulsive mass. If the flexibility of the tank wall is considered then the part of the impulsive mass moves independently while the remainder accelerates back and forth with the tank wall, and is known as rigid mass. The accelerating liquid, sloshing, impulsive and rigid masses induces substantial hydrodynamic pressures on the tank wall, which in turn generates design forces such as base shear and overturning moment.
The base shear is important from the isolator design view point while overturning moment produces significant tower deformation and toppling of the tower leads to failure of the tank. The failure of liquid storage tanks is mainly due to buckling of tank walls, toppling of the tower structure, failure of piping systems and uplift of the anchorage system. The seismic behaviour of the elevated liquid storage tank is highly complex due to liquid-structure-interaction leading to a tedious design procedure from seismic-resistant design point of view. Few studies to model ground supported liquid storage tanks and their dynamic response have been conducted to understand their behaviour. Housner [2] developed a theoretical lumped mass model of ground supported liquid storage tank with two-degrees-of-freedom, which were associated with convective and impulsive masses, to investigate the seismic response. It is observed that the liquid pressure generated due to earthquake ground motion is very important for seismic design of the tanks. Rosenblueth and Newmark [3] modified the expressions [2] to estimate the convective and impulsive masses to evaluate the seismic design forces of liquid storage tanks. Epstein [4] developed design charts for ground supported rigid liquid storage tanks to evaluate the design forces such as base shear and overturning moment

\footnotetext{
${ }^{1}$ Research Scholar, Dept. of Civil Engineering, Indian Institute of Technology Bombay.

${ }^{2}$ Assistant Professor, Dept. of Civil Engineering, Indian Institute of Technology

Bombay, Powai, Mumbai 400 076, India.
} 
A three-degree-of-freedom model of a ground supported deformable liquid storage tank developed by Haroun [5] derived design charts to estimate convective, impulsive and rigid masses with assumptions that the liquid contained in the tank was incompressible and had irrotational flow. The results of the theoretical model based upon finite element technique compared with response obtained by various codified recommendations, and emphasized there is need to investigate the response of the tanks accounting for the contribution of each component of fluid motion.

In order to protect the structure against earthquake hazard it is possible to strengthen conventionally, which may attract higher earthquake forces. An alternative technique to safe guard the structure is by isolation. The seismic isolation is achieved by implanting certain isolation devices to decouple from the ground to reduce peak response of the structure. Since the forces transmitted to the superstructure have been largely reduced, the superstructure can usually be expected to be linearly elastic, even under the excitation of severe earthquakes. The base isolation techniques have been developed and successfully implemented to buildings and bridges in the past [6-8]. A few studies of ground supported isolated liquid storage tanks were carried out and found that isolation was effective in reducing the response. Chalhoub and Kelly [9] observed that the sloshing response increases slightly but the total hydrodynamic pressures decreases substantially due to base isolation of the tanks. Kim and Lee [10] experimentally investigated the seismic performance of liquid storage tanks isolated by laminated rubber bearings under uni-directional excitation and showed that the isolation was effective in reducing the dynamic response. Malhotra [11-12] studied the seismic performance of liquid storage tanks under uni-directional ground motion, isolated by various techniques such as vertical isolation and lateral isolation. The studies indicated that the isolation techniques were quite effective in reducing the axial stresses in the cylindrical shell. The above studies confirmed that seismic isolation is effective in reducing the seismic response of the ground supported tanks. However, limited studies were conducted to investigate the effect of seismic isolation on the response of elevated liquid storage tanks. Bleiman and Kim [13] proposed the isolation as an effective method for rehabilitation of the elevated liquid storage tanks. Shenton III and Hampton [14] investigated the influence of the liquid's height on seismic response of the isolated elevated tank. But so far there has been no study, which investigates the performance of elevated liquid storage tanks isolated by nonlinear elastomeric bearings. In addition to this it will be interesting to investigate the response of the isolated tanks under a variation of different system parameters, which will be useful in understanding their dynamic behaviour for optimum design of the isolation system.

In this paper, earthquake response of elevated liquid storage tanks isolated by lead-rubber bearings is investigated under recorded earthquake ground motions. The specific objectives of this study are: (i) to investigate the seismic response of the isolated tanks considering the influence of various tank, tower and isolation parameters and compare with the response of a non-isolated tank to identify the effectiveness of the isolation system, (ii) to study comparative performance of base-isolated tanks when isolation bearings are placed at the top and bottom of the supporting tower structure, (iii) to determine the contribution of various components of base shear to total base shear and the influence of isolation on sloshing displacement and deformation of tower structure (i.e. tower drift), and (iv) to investigate the response of the isolated elevated liquid storage steel tanks by approximate models to minimize the computational efforts.

\section{STURCTURAL MODEL OF LIQUID STORAGE TANK}

Figure 1(a) shows the structural model of elevated liquid storage cylindrical tank mounted on a tower structure, which is fixed to the ground. The supporting system to the tank i.e. tower structure is considered as columnar type. The continuous liquid mass is lumped as convective, impulsive and rigid masses known as $m_{\mathrm{c}}, m_{\mathrm{i}}$ and $m_{\mathrm{r}}$, respectively. The convective and impulsive masses are connected to the tank wall by corresponding equivalent spring having stiffness $k_{\mathrm{c}}$ and $k_{\mathrm{i}}$, respectively. The damping constant of the convective and impulsive masses are $c_{\mathrm{c}}$ and $c_{\mathrm{i}}$, respectively. The tank has three-degrees-of-freedom under uni-directional excitation are $u_{\mathrm{c}}, u_{\mathrm{i}}$ and $u_{\mathrm{s}}$, which denote the absolute displacements of convective mass, impulsive mass and tower drift, respectively. The above mentioned elevated tank is isolated by two techniques, one by providing the isolation bearings below the tower structure as shown in Figure 1(b) (referred as isolated model-I) and the other form of isolation in which the isolation bearings are placed immediately below the cylindrical liquid tank as shown in Figure 1(c) (referred as isolated model-II). The additional degree-of-freedom created due to isolation of the tank, corresponds to the isolation system denoted as $u_{\mathrm{b}}$. The isolation system considered for this study is lead rubber-bearings, which have bi-linear forcedeformation behaviour.

It is assumed that the tower structure is firmly connected to the isolation bearings, which is effectively rigid in the vertical direction. Therefore, the influence of uplift and rocking are not considered in this study. Further, the self weight of steel tower structure and base mass (i.e. mass of base plate) are assumed as 10 percent and 5 percent of the tank liquid, respectively [14].

The parameters of the tanks considered are height of liquid $H$, radius, $R$ and average thickness of tank wall, $t_{h}$. The nondimensional parameters $Y_{c}, Y_{i}, Y_{r}$ and $P$ are function of the aspect ratio of the tank, $S$ and $t_{\mathrm{h}} / R$. For $t_{\mathrm{h}} / R=0.004$ [5] the non-dimensional parameters derived are expressed as

$$
\left\{\begin{array}{l}
Y_{c} \\
Y_{i} \\
Y_{r} \\
P
\end{array}\right\}=\left[\begin{array}{ccccc}
1.01327 & -0.8757 & 0.35708 & 0.06692 & 0.00439 \\
-0.15467 & 1.21716 & -0.62839 & 0.14434 & -0.0125 \\
-0.01599 & 0.86356 & -0.30941 & 0.04083 & 0 \\
0.037085 & 0.084302 & -0.05088 & 0.012523 & -0.0012
\end{array}\right]\left\{\begin{array}{l}
1 \\
S \\
S^{2} \\
S^{3} \\
S^{4}
\end{array}\right\}
$$

where $S=H / R$ is the aspect ratio (i.e. ratio the liquid height to radius of the tank) and $Y_{c}, Y_{i}$, and $Y_{\mathrm{r}}$ are the mass ratios defined as

$$
Y_{c}=\frac{m_{c}}{m}
$$


$Y_{i}=\frac{m_{i}}{m}$

$Y_{r}=\frac{m_{r}}{m}$

$m=\pi R^{2} H \rho_{w}$

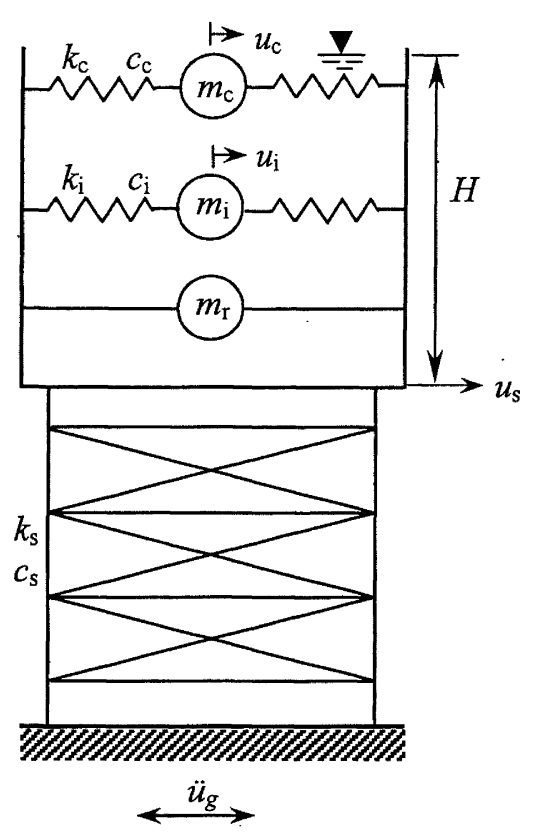

(a)

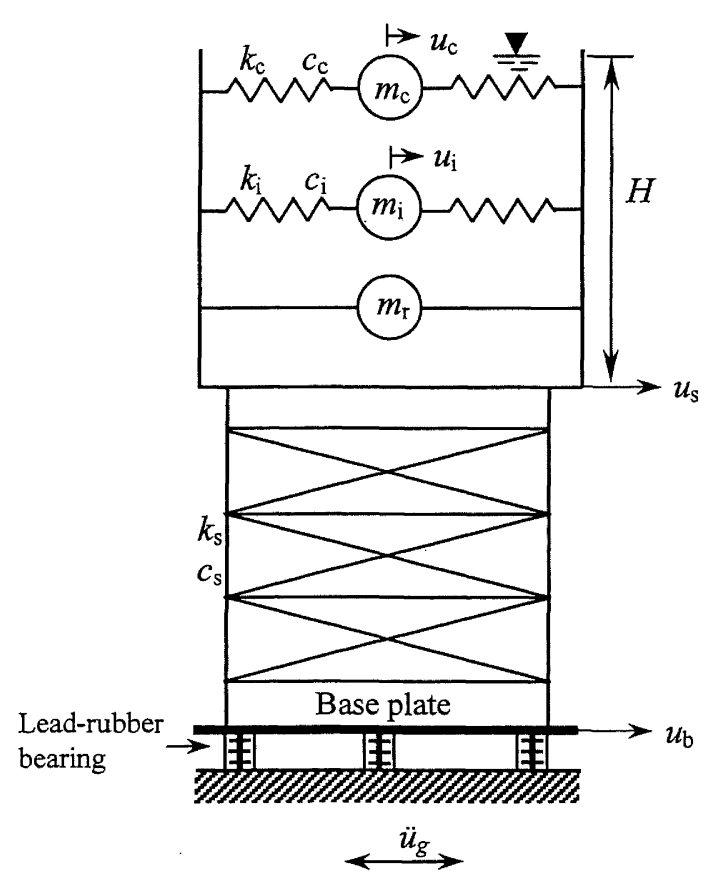

(b)

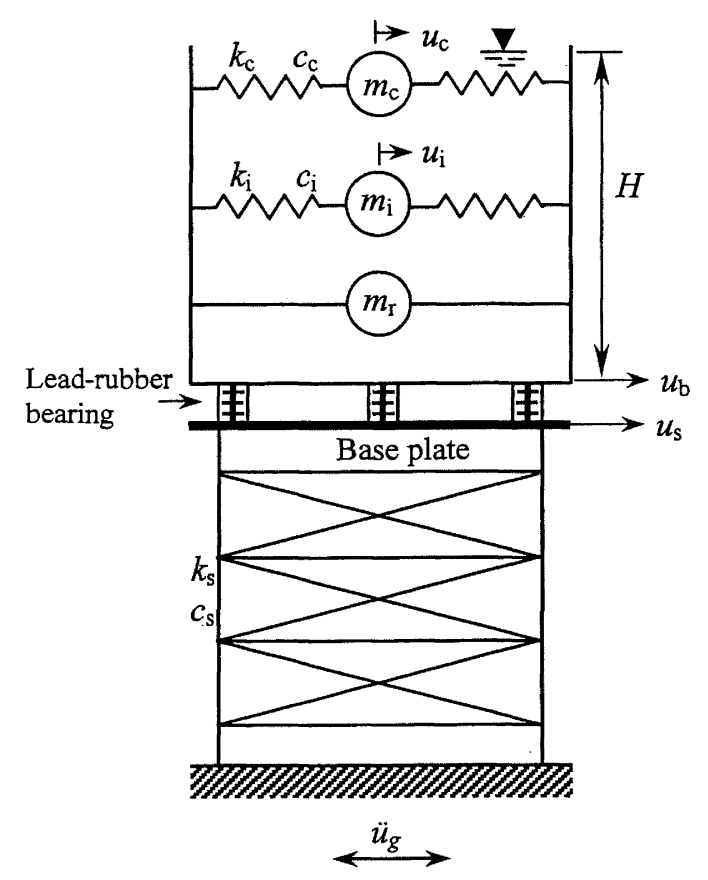

(c)

Figure 1. Model of elevated liquid storage tank: (a) non-isolated, (b) isolated model-I and (c) isolated model-II. 
The natural frequencies of sloshing mass, $\omega_{\mathrm{c}}$ and impulsive mass, $\omega_{\mathrm{i}}$ are given by following expressions [5] as

$$
\begin{aligned}
& \omega_{\mathrm{c}}=\sqrt{1.84\left(\frac{g}{R}\right) \tanh (1.84 S)} \\
& \omega_{\mathrm{i}}=\frac{P}{H} \sqrt{\frac{E}{\rho_{\mathrm{s}}}}
\end{aligned}
$$

where $g$ is the acceleration due to gravity; $E$ and $\rho_{\mathrm{s}}$ are the modulus of elasticity and density of tank wall, respectively.

The equivalent stiffness and damping of the convective and impulsive masses are expressed as

$$
\begin{aligned}
& k_{\mathrm{c}}=m_{\mathrm{c}} \omega_{\mathrm{c}}^{2} \\
& k_{\mathrm{i}}=m_{\mathrm{i}} \omega_{\mathrm{i}}^{2} \\
& c_{\mathrm{c}}=2 \xi_{\mathrm{c}} m_{\mathrm{c}} \omega_{\mathrm{c}} \\
& c_{\mathrm{i}}=2 \xi_{\mathrm{i}} m_{\mathrm{i}} \omega_{\mathrm{i}}
\end{aligned}
$$

where $\xi_{r}$ and $\xi_{i}$ are damping ratio of convective and impulsive masses, respectively.

\section{FORCE-DEFORMATION OF LEAD RUBBER BEARING}

The lead-rubber bearings considered here consist of alternate layers of rubber and steel plates with a central lead core, which is modelled by a bi-linear force-deformation hysteresis loop. The bearings are vertically rigid and have horizontal initial stiffness, $k_{\mathrm{b}}$ and viscous damping, $c_{\mathrm{b}}$, respectively. The vertical rigidity is derived from the steel plates while parallel layers of the rubber provide the horizontal flexibility. In order to measure the effectiveness, Robinson and Tucker [1516] conducted experimental test on lead-rubber bearings, which were positioned in building and bridges to isolate the structures against earthquakes. The test results revealed that the bearings were effective to control seismic response and their performance was satisfactory. The lead core yields at a relatively very low shear stress, leading to dissipation of seismic energy and reduction of earthquake response [17].

The restoring force in the isolation bearing is expressed by Wen's model [18] as

$$
F_{b}=\alpha k_{b} x_{b}+(1-\alpha) F_{y} Z
$$

where $k_{\mathrm{b}}$ is the pre-yielding stiffness of the bearing; $\alpha$ is an index, which represent the ratio of post to pre-yielding stiffness; $x_{b}$ is the relative displacement of bearings; $F_{y}$ is the yield strength of the bearing; and $Z$ is a non-dimensional parameter, which is computed from following non-linear first order differential equation

$q \frac{d Z}{d t}=A \dot{x}_{b}+\beta\left|\dot{x}_{b}\right| Z|Z|^{n-1}-\tau \dot{x}_{b}|Z|^{n}$

where $q$ is the yield displacement, $\dot{x}_{b}$ is the relative velocity of the bearing and $\beta, \tau, A$, and $n$ are non-dimensional parameters. The parameter $n$ is integer constant, which controls smoothness of transition from elastic to plastic state. The parameters $\beta, \tau, A$, and $n$ are selected such that the predicted response from the model closely matches with experimental results.

\section{GOVERNING EQUATIONS OF MOTION}

The equations of motion of elevated liquid storage tank subjected to unidirectional earthquake ground motion are expressed in the matrix form as

$$
[m]\{\ddot{x}\}+[c]\{\dot{x}\}+[k]\{x\}+\{F\}=-[m]\{r\} \ddot{u}_{g}
$$

where $\{x\}$ is displacement vector; $[m],[c]$ and $[k]$ are the mass, damping and stiffness matrix of the system, respectively; $\{F\}$ is the restoring force vector; $\{r\}$ is the influence coefficient vector; and $\ddot{u}_{\mathrm{g}}$ is the earthquake acceleration.

The displacement vector for a non-isolated tank is given by $\{x\}=\left\{x_{\mathrm{c}}, x_{\mathrm{i}}, x_{\mathrm{s}}\right\}^{T} ; x_{\mathrm{c}}=u_{\mathrm{c}}-u_{\mathrm{s}}$ is the displacement of the convective mass, $x_{\mathrm{i}}=u_{\mathrm{i}}-u_{\mathrm{s}}$ is the displacement of the impulsive mass; $x_{s}=u_{\mathrm{s}}-u_{\mathrm{g}}$ is the tower drift relative to ground. The vector $\{F\}$ is a null vector for a non-isolated tank. The matrices $[m],[c],[k]$ and the vector $\{r\}$ for nonisolated tank are expressed as

$$
\begin{aligned}
& {[m]=\left[\begin{array}{ccc}
m_{\mathrm{c}} & 0 & m_{\mathrm{c}} \\
0 & m_{\mathrm{i}} & m_{\mathrm{i}} \\
m_{\mathrm{c}} & m_{\mathrm{i}} & M+m_{\mathrm{b}}
\end{array}\right]} \\
& {[c]=\operatorname{diag}\left[c_{\mathrm{c}}, c_{\mathrm{i}}, c_{\mathrm{s}}\right]} \\
& {[k]=\operatorname{diag}\left[k_{\mathrm{c}}, k_{\mathrm{i}}, k_{\mathrm{s}}\right]} \\
& \{r\}=\{0,0,1\}^{T}
\end{aligned}
$$

where $M=m_{\mathrm{c}}+m_{\mathrm{i}}+m_{\mathrm{r}}$ is the effective mass of the tank and $m_{b}$ is equal to $0.05 \mathrm{~m}$. 
The stiffness, $k_{\mathrm{s}}$ and damping, $c_{\mathrm{s}}$ of the tower structure, based on the assumption of simple single-degree-of-freedom system, are expressed as

$$
\begin{aligned}
& k_{\mathrm{s}}=\left(\frac{2 \pi}{T_{\mathrm{s}}}\right)^{2}(M+0.05 m) \\
& c_{\mathrm{s}}=2 \xi_{\mathrm{s}}(M+0.05 m) \omega_{\mathrm{s}}
\end{aligned}
$$

where $T_{\mathrm{s}}$ and $\xi_{\mathrm{s}}$ are time period and damping ratio of the tower structure, respectively and $\omega_{\mathrm{s}}$ is frequency of tower structure.

The displacement vector for the isolated model-I is expressed as $\{x\}=\left\{x_{\mathrm{c}}, x_{\mathrm{i}}, x_{\mathrm{s}}, x_{\mathrm{b}}\right\}^{T} ; x_{\mathrm{c}}=u_{\mathrm{c}}-u_{\mathrm{s}}$ is the displacement of the convective mass, $x_{\mathrm{i}}=u_{\mathrm{i}}-u_{\mathrm{s}}$ is the displacement of the impulsive mass; $x_{\mathrm{s}}=u_{\mathrm{s}}-u_{\mathrm{b}}$ is the tower drift and $x_{\mathrm{b}}=u_{\mathrm{b}}-u_{\mathrm{g}}$ is the bearing displacement relative to ground. The matrices $[m],[c],[k]$ and the vectors $\{r\}$ and $\{F\}$ are expressed as

$$
\begin{gathered}
{[m]=\left[\begin{array}{cccc}
m_{\mathrm{c}} & 0 & m_{\mathrm{c}} & m_{\mathrm{c}} \\
0 & m_{\mathrm{i}} & m_{\mathrm{i}} & m_{\mathrm{i}} \\
m_{\mathrm{c}} & m_{\mathrm{i}} & M+m_{\mathrm{b}} & M+m_{\mathrm{b}} \\
m_{\mathrm{c}} & m_{\mathrm{i}} & M+m_{\mathrm{b}} & M+3 m_{\mathrm{b}}
\end{array}\right]} \\
{[c]=\operatorname{diag}\left[c_{\mathrm{c}}, c_{\mathrm{i}}, c_{\mathrm{s}}, c_{\mathrm{b}}\right]} \\
{[k]=\operatorname{diag}\left[k_{\mathrm{c}}, k_{\mathrm{i}}, k_{s}, \alpha k_{\mathrm{b}}\right]} \\
\{r\}=\{0,0,0,1\}^{T} \\
\{F\}=\left\{0,0,0,(1-\alpha) F_{y} Z\right\}^{T}
\end{gathered}
$$

The stiffness, $k_{\mathrm{b}}$ and damping, $c_{\mathrm{b}}$ of the isolation are defined as

$$
\begin{aligned}
& k_{\mathrm{b}}=\left(\frac{2 \pi}{T_{\mathrm{b}}}\right)^{2}(M+0.15 m) \\
& c_{\mathrm{b}}=2 \xi_{\mathrm{b}}\left(M^{\circ}+0.15 m\right) \omega_{\mathrm{b}}
\end{aligned}
$$

where $T_{\mathrm{b}}$ and $\xi_{\mathrm{h}}$ are the time period and damping ratio of the isolation system; $\omega_{\mathrm{b}}$ is the isolation frequency; tower stiffness and damping are computed using Eqs.(19) and (20), respectively.

Similarly, the displacement vector for the isolated model-II is expressed as $\{x\}=\left\{x_{\mathrm{c}}, x_{\mathrm{i}}, x_{\mathrm{b}}, x_{\mathrm{s}}\right\}^{T} ; x_{\mathrm{c}}=u_{\mathrm{c}}-u_{\mathrm{b}}$ is the displacement of the convective mass, $x_{\mathrm{i}}=u_{\mathrm{i}}-u_{\mathrm{b}}$ is the displacement of the impulsive mass; $x_{\mathrm{b}}=u_{\mathrm{b}}-u_{\mathrm{s}}$ is the bearing displacement; $x_{\mathrm{s}}=u_{\mathrm{s}^{-}} u_{\mathrm{g}}$ is the relative displacement of the tower to ground. The matrices $[m],[c],[k]$ and the vectors $\{r\}$ and $\{F\}$ are expressed as

$$
\begin{aligned}
& {[m]=\left[\begin{array}{cccc}
m_{\mathrm{c}} & 0 & m_{\mathrm{c}} & m_{\mathrm{c}} \\
0 & m_{\mathrm{i}} & m_{\mathrm{i}} & m_{\mathrm{i}} \\
m_{\mathrm{c}} & m_{\mathrm{i}} & M & M \\
m_{\mathrm{c}} & m_{\mathrm{i}} & M & M+2 m_{\mathrm{b}}
\end{array}\right]} \\
& {[c]=\operatorname{diag}\left[c_{\mathrm{c}}, c_{\mathrm{i}}, c_{\mathrm{b}}, c_{\mathrm{s}}\right]} \\
& {[k]=\operatorname{diag}\left[k_{\mathrm{c}}, k_{\mathrm{i}}, \alpha k_{\mathrm{b}}, k_{\mathrm{s}}\right]} \\
& \{r\}=\{0,0,0,1\}^{T} \\
& \{F\}=\left\{0,0,(1-\alpha) F_{\mathrm{y}} Z, 0\right\}^{T}
\end{aligned}
$$

The stiffness and damping of the isolation system and tower structure are expressed as

$$
\begin{aligned}
& k_{\mathrm{s}}=\left(\frac{2 \pi}{T_{\mathrm{s}}}\right)^{2}(M+0.1 m) \\
& k_{\mathrm{b}}=\left(\frac{2 \pi}{T_{\mathrm{b}}}\right)^{2} M \\
& c_{\mathrm{s}}=2 \xi_{\mathrm{s}}(M+0.1 m) \omega_{\mathrm{s}} \\
& c_{\mathrm{b}}=2 \xi_{\mathrm{b}} M \omega_{\mathrm{b}}
\end{aligned}
$$

Since the damping in the different components of an isolated liquid storage tank is different in magnitude because of different material characteristics, as a result, the equations of motion cannot be solved using classical modal superposition technique. Alternatively, the equations of motion are solved in the incremental form of using Newmark's step-by-step method assuming linear variation of acceleration over a small time interval, $\Delta t$. In each time step the incremental hysteretic displacement, $Z$ is evaluated by a third order Runge-Kutta method.

After obtaining the acceleration vector the base shear is computed, which is directly proportional to the earthquake forces transmitted to the tank, as result of seismic excitation of the tank is expressed as

$$
F_{b}=m_{\mathrm{c}} \ddot{u}_{\mathrm{c}}+m_{\mathrm{i}} \ddot{u}_{\mathrm{i}}+\left(m_{\mathrm{r}}+0.05 m\right) \ddot{u}_{\mathrm{s}}
$$

(for non-isolated)

$F_{b}=m_{\mathrm{c}} \ddot{u}_{\mathrm{c}}+m_{\mathrm{i}} \ddot{u}_{\mathrm{i}}+\left(m_{\mathrm{r}}+0.05\right) \ddot{u}_{\mathrm{s}}+2 m_{\mathrm{b}} \ddot{u}_{\mathrm{b}}$ 
(for isolated model-I)

$$
F_{b}=m_{\mathrm{c}} \ddot{u}_{\mathrm{c}}+m_{\mathrm{i}} \ddot{u}_{\mathrm{i}}+m_{\mathrm{r}} \ddot{u}_{\mathrm{b}}+2 m_{\mathrm{b}} \ddot{u}_{\mathrm{s}}
$$

(for isolated model-II)

\section{NUMERICAL STUDY}

The seismic response of elevated isolated liquid storage tanks, namely slender and broad tanks, has been investigated. The properties of these tanks are: (i) the aspect ratio, $S$ for slender and broad tanks is 1.85 and 0.6 , respectively, (ii) the height, $H$, of water filled in the slender and broad tanks is $10 \mathrm{~m}$. The natural frequencies of convective and impulsive mass are 0.291 and $6.738 \mathrm{~Hz}$ (for slender tank) and 0.148 and $5.757 \mathrm{~Hz}$ (for broad tank). The modulus of elasticity and mass density of tank wall considered are: $E=200 \mathrm{MPa}$ and $\rho_{s}=7,900 \mathrm{~kg} / \mathrm{m}^{3}$, respectively. The isolation parameters selected for the study are held constant and their values taken are: $q=25 \mathrm{~mm}, A=1, \beta=0.5, \tau=0.5$ and $n=2$. The ratio of post to pre-yielding stiffness of the bearing is computed using the expression $\alpha=\omega_{b}^{2} M q / F_{y}$. The damping ratio for the convective mass $\left(\xi_{\mathrm{c}}\right)$ and the impulsive mass $\left(\xi_{\mathrm{i}}\right)$ are taken as 0.5 percent and 2 percent, respectively. The seismic response of the isolated tank is investigated for two tank models one in which the entire structure is isolated (refer Figure 1(b)) and another model in which only the liquid tank is isolated by positioning bearings at the top of the tower structure (refer Figure 1(c)). The response quantities of interest are base shear (measured at bottom of the foundation level of the structure), $F_{\mathrm{b}} / W(W=M g)$, sloshing displacement $\left(x_{\mathrm{c}}\right)$, drift of tower structure $\left(x_{\mathrm{s}}\right)$ and displacement at top of the interface of isolation bearings, $x_{\mathrm{b}}$. For the present study, the components $\mathrm{N} 00 \mathrm{E}, \mathrm{S} 00 \mathrm{E}$ and NOOE of the Northridge (1994), Imperial Valley (1940) and Kobe (1995) earthquake ground motions, respectively, are used to investigate the response of the tank. The peak ground acceleration of the Northridge, Imperial Valley and Kobe earthquake records are $0.843 \mathrm{~g}, 0.348 \mathrm{~g}$ and $0.834 \mathrm{~g}$, respectively

Figures 2 and 3 show the time variation of response of the elevated slender and broad tanks, respectively, under the Northridge, 1994 earthquake. The model parameters considered were $T_{\mathrm{b}}=2 \mathrm{sec}, \xi_{\mathrm{b}}=0.05, T_{\mathrm{s}}=0.5 \mathrm{sec}$ and normalized yield strength $\left(F_{y} / W\right)$ i.e. $F_{0}=0.05$. The figures indicate that the variation of the response of the two isolated tank models (i.e. isolated model-I and isolated model-II) is identical and closely matched. The base shear and tower drift of the isolated tanks are significantly reduced in comparison to corresponding non-isolated tanks. The peak bearing displacement in a slender tank for isolated model-I and isolated model-II are $444.5 \mathrm{~mm}$ and $435.2 \mathrm{~mm}$, respectively while for a broad tank the corresponding displacements are $370.1 \mathrm{~mm}$ and $329.4 \mathrm{~mm}$. This indicates that bearing displacement is comparatively less in the broad tank case. It was also observed that the bearing displacement produced in the isolated model-II was marginally less in comparison to isolated model-I. It was found that the increase of sloshing displacement in slender tank was comparatively more in the broad tank.
The Tables 1 and 2 show the comparative study of the peak response of the isolated elevated slender and broad tanks against corresponding non-isolated tanks for two different values of period of tower structure (i.e. $T_{\mathrm{s}}=0.5 \mathrm{sec}$ and 1 $\mathrm{sec})$, respectively. The isolation parameters considered are $T_{\mathrm{b}}$ $=2 \mathrm{sec}, \xi_{\mathrm{b}}=0.05$ and $F_{0}=0.05$. The tables show that for the slender tank the percentage reduction in base shear, as a result of isolation, at $T_{\mathrm{s}}=0.5 \mathrm{sec}$ for isolated model-I is $76.38,86.14$ and 86.17 under Northridge, Imperial Valley, and Kobe earthquakes, respectively, while the corresponding reduction at $T_{\mathrm{s}}=1 \mathrm{sec}$ is $40.03,82.05$ and 82.66 . Similarly, for broad tank the corresponding reduction at $T_{\mathrm{s}}=0.5 \mathrm{sec}$ and $1 \mathrm{sec}$ are: $75.39,75.12$ and 76.11 and $40.75,74.59$ and 72.79 . For isolated model-II the percentage reduction in base shear for slender tank at $T_{\mathrm{s}}=0.5 \mathrm{sec}$ and $T_{\mathrm{s}}=1 \mathrm{sec}$ are 78.56, 86.62 and 87.72 and $42.15,82.68$ and 84.39 , respectively. Similarly for a broad tank the corresponding reduction are $77.70,76.37$ and 77.63 and $45.99,74.86$ and 71.59. The above results indicate that due to isolation of the tanks base shear was reduced significantly. The reduction in base shear is comparatively greater in the slender tank. In addition to this it is also observed that the reduction in base shear for isolated model-II is slightly greater in comparison to the isolated model-I. The comparative results indicate that reduction in the base shear is slightly more in tank with a stiff tower structure. The percentage reduction in tower displacement for slender tank (i.e. tower drift) in isolated model-I at $T_{\mathrm{s}}=0.5$ sec and $T_{\mathrm{s}}=1 \mathrm{sec}$ is $77.65,86.89$ and 86.87 and $43.47,82.98$ and 83.07 , respectively. For broad tank the corresponding reduction are $77.36,77.11$ and 78.09 and $44.34,76.18$ and 74.31. Similarly, for slender tank percentage reduction in tower drift for isolated model-II is $79.58,87.28$ and 88.39 and $45.77,83.75$ and 84.99 , respectively while for broad tank the corresponding reduction is $79.45,77.91$ and 79.17 and $49.64,76.41$ and 74.25 . These results indicate that tower drift was significantly reduced, as a result of isolation, and this was more pronounced when the tower structure is comparatively rigid. It is also observed that the increased flexibility of the tower structure transmitted less earthquake forces but it increased tower drift significantly. This implies that for the stiff tower structure the reduction in the response achieved was more in comparison to the flexible tower structure. The peak sloshing displacement was increased significantly in slender tank while in broad tank the increase of sloshing displacement due to isolation was less (except due to Imperial Valley earthquake).

\section{Effects of Tank Aspect Ratio}

In order to investigate the response of the tanks for a wide range of practical elevated liquid storage tanks the responses are plotted against tank aspect ratio, $S$. Figure 4 shows the variation of different components of base shear such as convective, impulsive, rigid and base under the Northridge, Imperial Valley and Kobe earthquakes for isolated and nonisolated conditions. The isolation parameters considered were $T_{\mathrm{b}}=2 \mathrm{sec}, T_{\mathrm{s}}=0.5, \xi_{\mathrm{b}}=0.05$ and $F_{0}=0.05$. It was observed that the contribution of convective component was slightly increased due to isolation but its over all contribution to total base shear was negligible, hence did not influence the response. The equal contribution of rigid component and impulsive component to total base shear up to aspect ratio $S$ $=1.5$, and beyond that rigid component had slightly more contribution in comparison to impulsive component. This difference was slightly modified and the difference was slightly increased due to isolation of the tank. It is also 


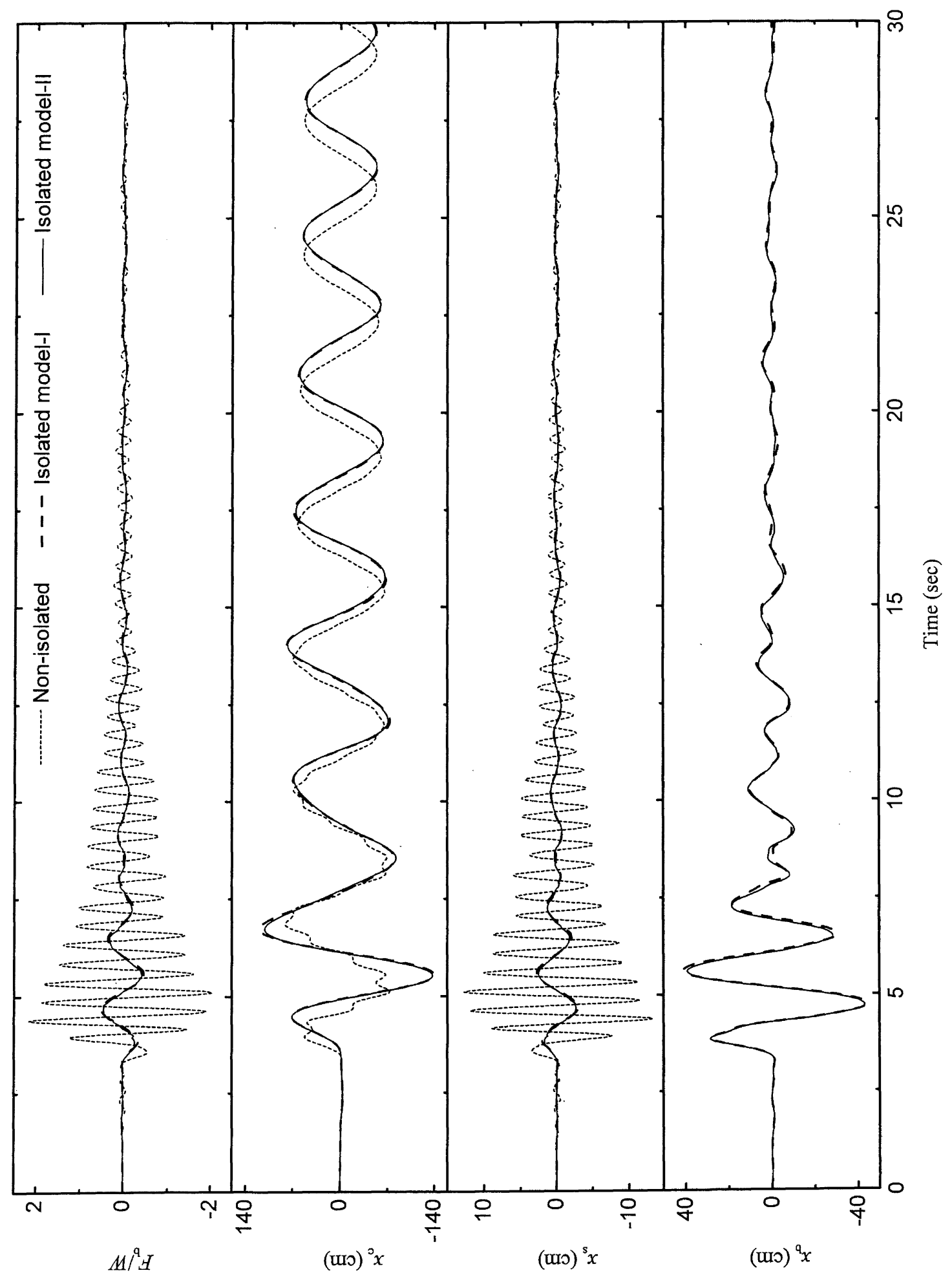

Figure 2. Time variation of slender tank response under Northridge, 1994 earthquake $\left(T_{b}=2 \mathrm{sec}, \xi_{b}=0.05, T_{s}=0.5\right.$ sec and $F_{0}=0.05$ ). 


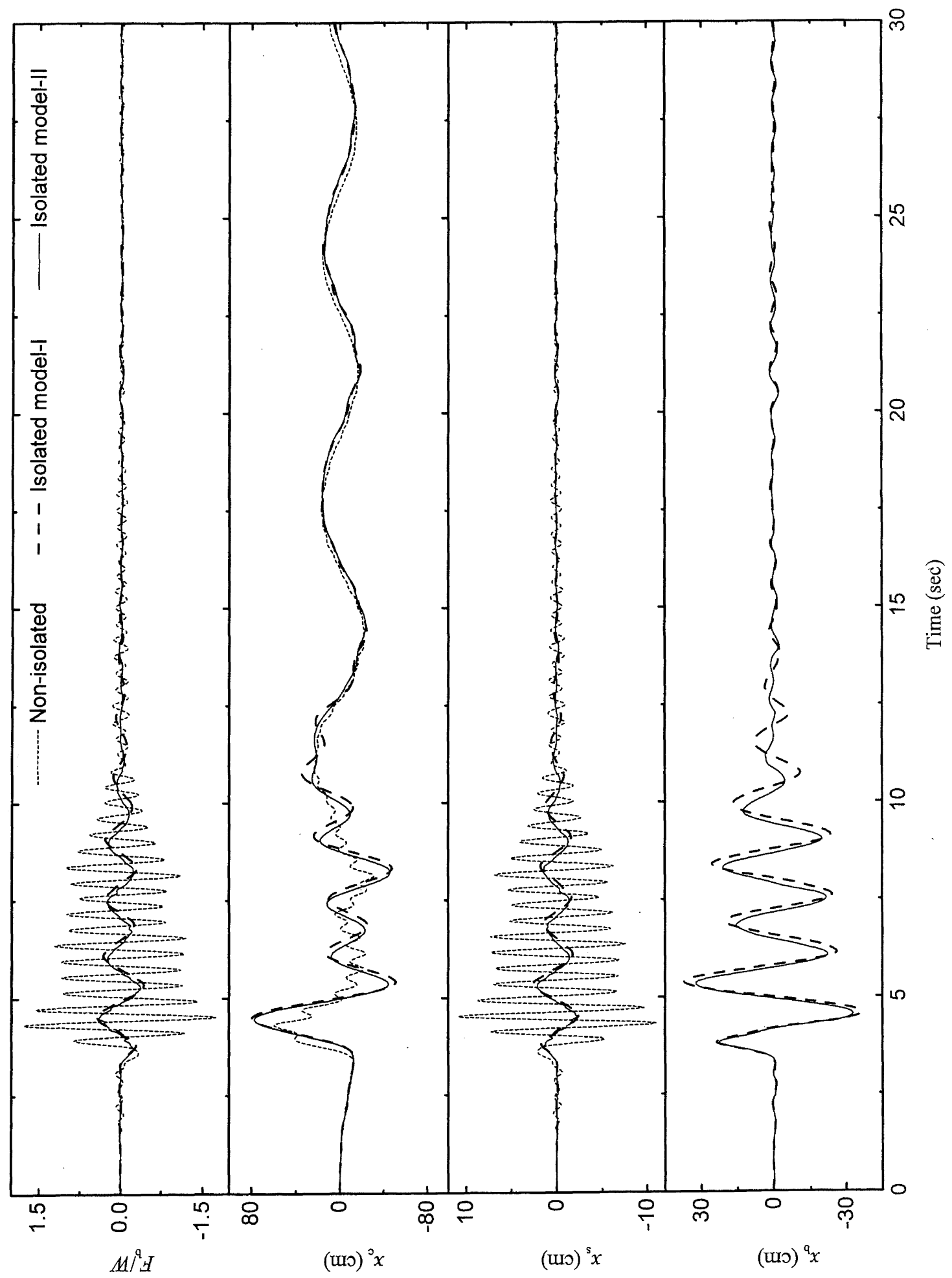

Figure 3. Time variation of broad tank response under Northridge, 1994 earthquake $\left(T_{b}=2 \mathrm{sec}, \xi_{b}=0.05, T_{s}=0.5\right.$ sec and $F_{0}$ $=0.05$ ). 
observed that the base component had negligible contribution. The variation of peak sloshing displacement, tower drift and bearing displacement against aspect ratio are illustrated in Figure 5. The sloshing displacement increased as the aspect ratio increases for non-isolated and isolated tanks. This implies that sloshing was more in a slender tank compared to a broad tank, which are amplified by isolation of the tank. But the tower displacement is significantly reduced due to isolation and the two isolated tank models predicted similar variation. Initially, increases in the bearing displacement was significant and beyond aspect ratio, $S=1.5$ the variation caused a marginal increase in the bearing displacement. It was also observed that the two models of the isolated tanks predicted identical bearing displacement.

Table 1 Peak seismic response of elevated slender tank $\left(T_{b}=2 \mathrm{sec}, \xi_{\mathrm{b}}=0.05\right.$ and $\left.F_{0}=0.05\right)$

\begin{tabular}{|c|c|c|c|c|c|c|c|c|c|}
\hline \multirow[t]{2}{*}{ Earthquake } & \multirow[t]{2}{*}{ Type of tank } & \multicolumn{4}{|c|}{$T_{\mathrm{s}}=0.5 \mathrm{sec}$} & \multicolumn{4}{|c|}{$T_{\mathrm{s}}=1.0 \mathrm{sec}$} \\
\hline & & $F_{\mathrm{b}} / W$ & $x_{\mathrm{c}}(\mathrm{cm})$ & $x_{\mathrm{s}}(\mathrm{cm})$ & $x_{\mathrm{b}}(\mathrm{cm})$ & $F_{\mathrm{b}} / W$ & $x_{\mathrm{c}}(\mathrm{cm})$ & $x_{\mathrm{s}}(\mathrm{cm})$ & $\begin{array}{c}x_{\mathrm{b}} \\
(\mathrm{cm})\end{array}$ \\
\hline \multirow{3}{*}{$\begin{array}{c}\text { Northridge, } \\
1994\end{array}$} & Non-isolated & 2.164 & 81.54 & 13.42 & - & 0.771 & 89.48 & 19.14 & - \\
\hline & Isolated model-I & 0.511 & 140.53 & 3.00 & 44.45 & 0.462 & 145.49 & 10.82 & 40.05 \\
\hline & Isolated model-II & 0.464 & 137.64 & 2.74 & 43.52 & 0.446 & 143.01 & 10.38 & 39.34 \\
\hline \multirow{3}{*}{$\begin{array}{c}\text { Imperial } \\
\text { Valley, } 1940\end{array}$} & Non-isolated & 0.837 & 32.85 & 5.19 & - & 0.635 & 35.44 & 15.75 & - \\
\hline & Isolated model-I & 0.116 & 36.79 & 0.68 & 8.53 & 0.114 & 38.76 & 2.68 & 8.31 \\
\hline & Isolated model-II & 0.112 & 35.81 & 0.66 & 8.19 & 0.110 & 37.87 & 2.56 & 7.87 \\
\hline \multirow{3}{*}{ Kobe, 1995} & Non-isolated & 2.654 & 47.01 & 16.46 & - & 1.742 & 68.76 & 43.19 & - \\
\hline & Isolated model-I & 0.367 & 72.19 & 2.16 & 31.22 & 0.302 & 73.37 & 7.31 & 25.73 \\
\hline & Isolated model-II & 0.326 & 70.57 & 1.91 & 30.46 & 0.272 & 72.72 & 6.48 & 26.89 \\
\hline
\end{tabular}

\section{Effects of Time Period of Tower Structure}

Figure 6 shows the effects of period of tower structure, $T_{\mathrm{s}}$ on response of isolated slender tanks under various earthquakes. It was found that the variation of $T_{\mathrm{s}}$ does not significantly influence the response of isolated tank. The responses predicted by the two tank models were identical. The comparison of response of the isolated and non-isolated tanks indicates significant reduction in base shear while sloshing displacement was increased due to isolation. The two tank models predicted identical bearing displacement. For the broad tank a similar effect was observed as depicted in the Figure 7 . Thus, it is concluded that the increasing flexibility of the tower structure does not influence the response of the isolated tanks.

\section{Effects of Bearing Damping}

The effect of isolation damping on the response of slender tank predicted by the two isolated tank models is illustrated in Figure 8. The figure indicates that base shear, sloshing displacement and bearing displacement reduces as the damping increases. It has been found that base shear decreases as the bearing damping increases and attains a minimum value, further increases of the damping increases the base shear. The sloshing displacement gradually decreases as bearing damping increases. The reduction in bearing displacement was significant due to increase of bearing damping which was obvious. Figure 9 depicts the similar behaviour of the broad tank and response obtained by the two tank models. This indicates that there exist an optimum bearing damping and appropriate selection of the bearing damping is important to achieve the minimum response of the isolated tank. 
Table 2 Peak seismic response of elevated broad $\operatorname{tank}\left(T_{\mathrm{b}}=2 \mathrm{sec}, \xi_{\mathrm{b}}=0.05\right.$ and $\left.F_{0}=0.05\right)$

\begin{tabular}{|c|c|c|c|c|c|c|c|c|c|}
\hline \multirow[t]{2}{*}{ Earthquake } & \multirow[t]{2}{*}{ Type of tank } & \multicolumn{4}{|c|}{$T_{\mathrm{s}}=0.5 \mathrm{sec}$} & \multicolumn{4}{|c|}{$T_{\mathrm{s}}=1.0 \mathrm{sec}$} \\
\hline & & $F_{\mathrm{b}} / W$ & $\begin{array}{c}x_{\mathrm{c}} \\
(\mathrm{cm})\end{array}$ & $\begin{array}{c}x_{\mathrm{s}} \\
(\mathrm{cm})\end{array}$ & $\begin{array}{c}x_{\mathrm{b}} \\
(\mathrm{cm})\end{array}$ & $F_{\mathrm{b}} / W$ & $\begin{array}{c}x_{\mathrm{c}} \\
(\mathrm{cm})\end{array}$ & $\begin{array}{c}x_{\mathrm{s}} \\
(\mathrm{cm})\end{array}$ & $\begin{array}{c}x_{\mathrm{b}} \\
(\mathrm{cm})\end{array}$ \\
\hline \multirow{3}{*}{$\begin{array}{c}\text { Northridge, } \\
1994\end{array}$} & Non-isolated & 1.776 & 59.71 & 11.00 & - & 0.724 & 61.93 & 17.93 & - \\
\hline & Isolated model-I & 0.437 & 79.55 & 2.49 & 37.01 & 0.429 & 81.92 & 9.98 & 36.74 \\
\hline & Isolated model-II & 0.396 & 77.31 & 2.26 & 32.94 & 0.391 & 80.81 & 9.03 & 34.54 \\
\hline \multirow{3}{*}{$\begin{array}{c}\text { Imperial } \\
\text { Valley, } 1940\end{array}$} & Non-isolated & 0.402 & 30.63 & 2.49 & - & 0.366 & 30.08 & 9.07 & - \\
\hline & Isolated model-I & 0.100 & 28.14 & 0.57 & 6.96 & 0.093 & 29.83 & 2.16 & 6.40 \\
\hline & Isolated model-II & 0.095 & 28.09 & 0.55 & 6.68 & 0.092 & 29.16 & 2.14 & 6.14 \\
\hline \multirow{3}{*}{ Kobe, 1995} & Non-isolated & 1.511 & 31.95 & 9.36 & - & 1.246 & 47.28 & 30.87 & - \\
\hline & Isolated model-I & 0.361 & 44.64 & 2.05 & 30.27 & 0.339 & 43.17 & 7.93 & 28.59 \\
\hline & Isolated model-II & 0.338 & 45.48 & 1.95 & 28.72 & 0.354 & 43.96 & 7.95 & 26.98 \\
\hline
\end{tabular}

\section{Effects of Yield Strength of Bearings}

Figures 10 and 11 illustrate the influence of yield strength on response of slender and broad tanks, respectively. The figures indicate that both the models predict the identical response for both tanks. Furthermore, initially the base shear decreased as yield strength increased and attained a minimum value and beyond that it increases with the yield strength, implying that there exists an optimum value of the yield strength. In addition to this, sloshing displacement decreased as yield strength increased. The bearing displacement decreased with increases in yield strength for both the tank models, which is obvious since yield strength increased the rigidity of the bearing, hence transmitting greater accelerations, which in turn increased the base shear. Therefore, the optimum value of yield strength should be selected such that a balance is maintained between earthquake forces transmitted to the tank and bearing displacement induced.

\section{Effects of Time Period of Bearings}

Figure 12 shows the influence of time period of isolation system on the response of slender tank. It was observed that the both tank models predict similar response, which were closely matched, implying the behaviour of the tower structure as a rigid body (i.e. tower drift is very small in the isolated tanks refer Figure 5). It is observed that base shear was reduced significantly as bearing time period increased. The sloshing displacement marginally increased with increase of time period and peaked in vicinity of $3 \mathrm{sec}$ which is close to period of sloshing mass (i.e. $3.66 \mathrm{sec}$ ) and a further increase in period reduced the sloshing displacement (except Kobe earthquake). The bearing displacement increased as time period of the isolation system increased. Similar result were observed for a broad tank as shown in Figure 13 except sloshing displacement. The sloshing displacement is not significantly influenced by variation of the isolation period. This is due to fact that the period of sloshing mass and range of isolation period considered are well separated.

\section{SIMPLIFIED RESPONSE ANALYSIS OF ISOLATED ELEVATED TANKS}

The previous study indicates that the impulsive displacement is considerably less in comparison to the other displacements, which further reduces due to isolation. It is also observed that as a result of isolation of the elevated tank, deformation in the tower structure is very small. Therefore, it will be interesting to investigate the earthquake response of the isolated elevated liquid storage tank considering that impulsive mass rigidly moves with the tank wall as a rigid mass and deformation of the tower structure is negligible (refer Figure 5). Hence, the reduced degree-of-freedom models of the isolated tanks are shown in Figure 14. The period of sloshing mass is quite high and well separated from the period of isolation bearings. Therefore, it will be interesting to investigate the response of tanks by assuming that the sloshing mass moves independently of the base motion. This assumption will generate two types of models 
one in which the motion of the sloshing mass is coupled with motion of the base mass (i.e. is called coupled model) and another in which two masses have independent motion (i.e. decoupled model). The equations of the motion for the two tank models were solved numerically and the response obtained by both decoupled and coupled analysis was compared.
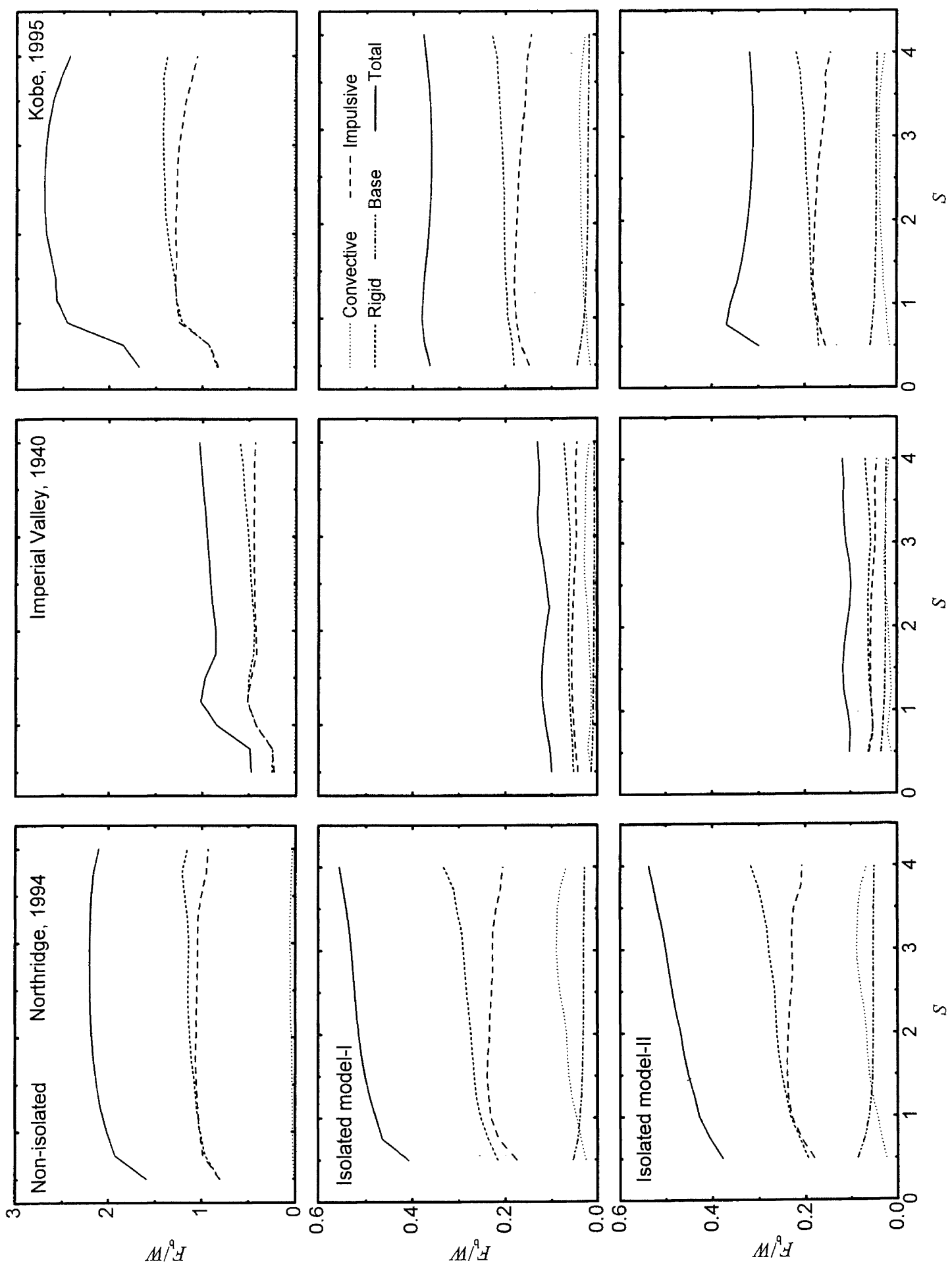

Figure 4. Variation of base shear components of elevated tank against aspect ratio $\left(T_{b}=2 \mathrm{sec}, \xi_{b}=0.05, T_{s}=0.5\right.$ sec and $F_{0}=$ 0.05). 


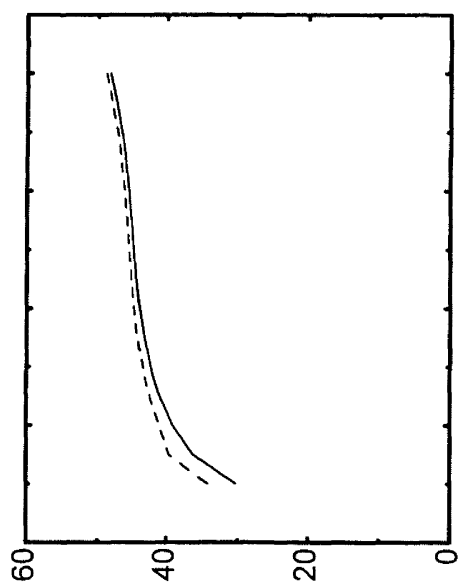

(wo) ${ }^{9} x$

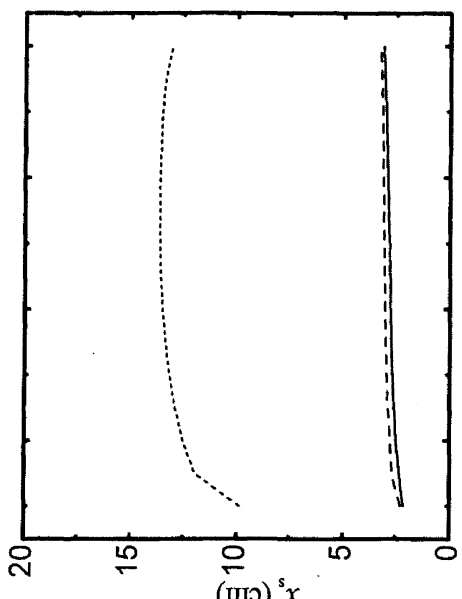

(ய0) ${ }^{s} x$

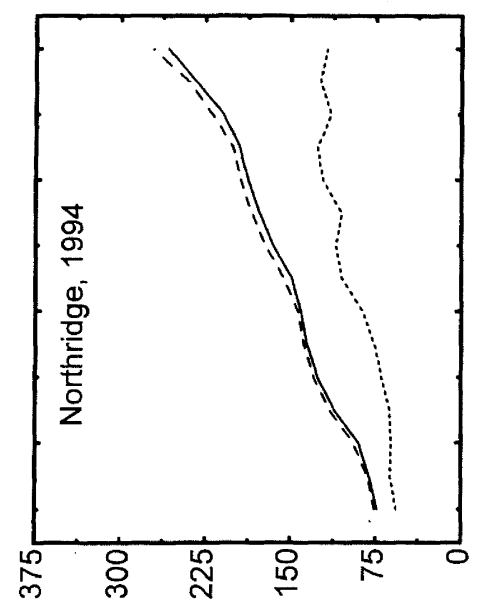

(ய) ${ }^{2} x$

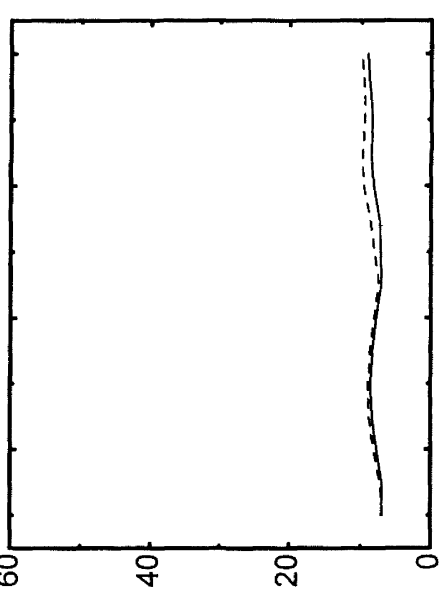

(سо) ${ }^{9} x$

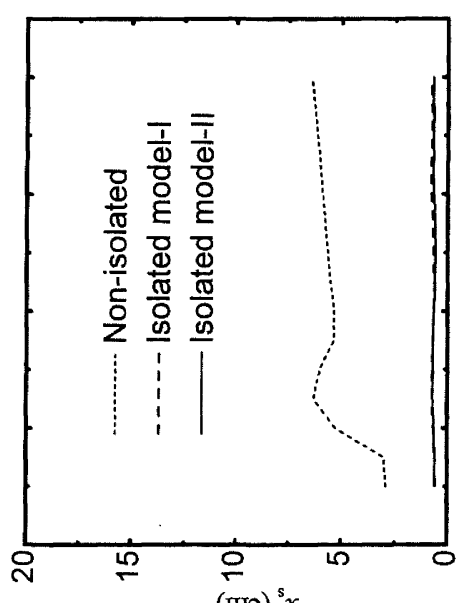

(wi) ${ }^{5} x$

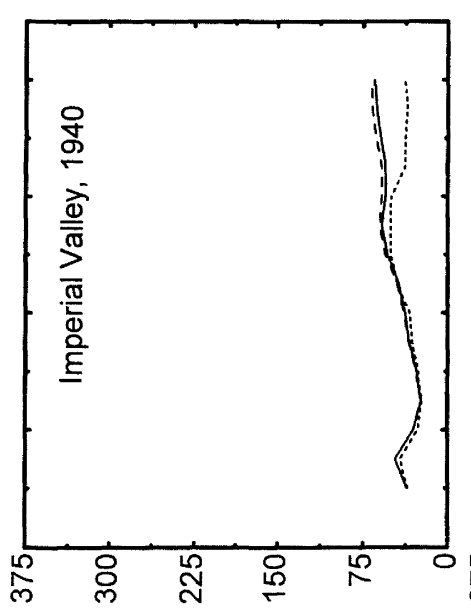

(wo) ${ }^{2} x$

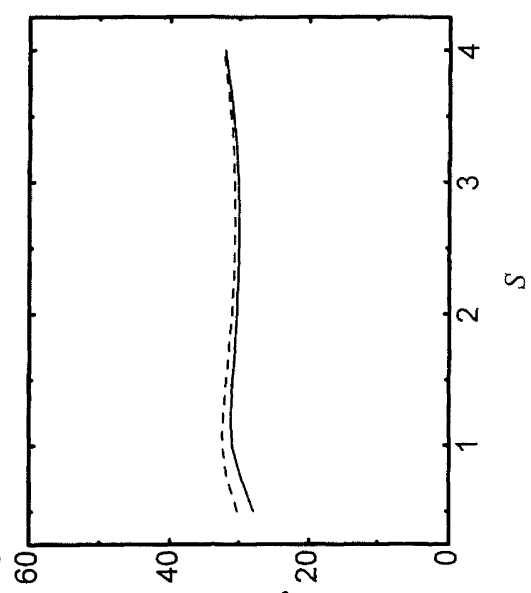

(wo) ${ }^{9} x$
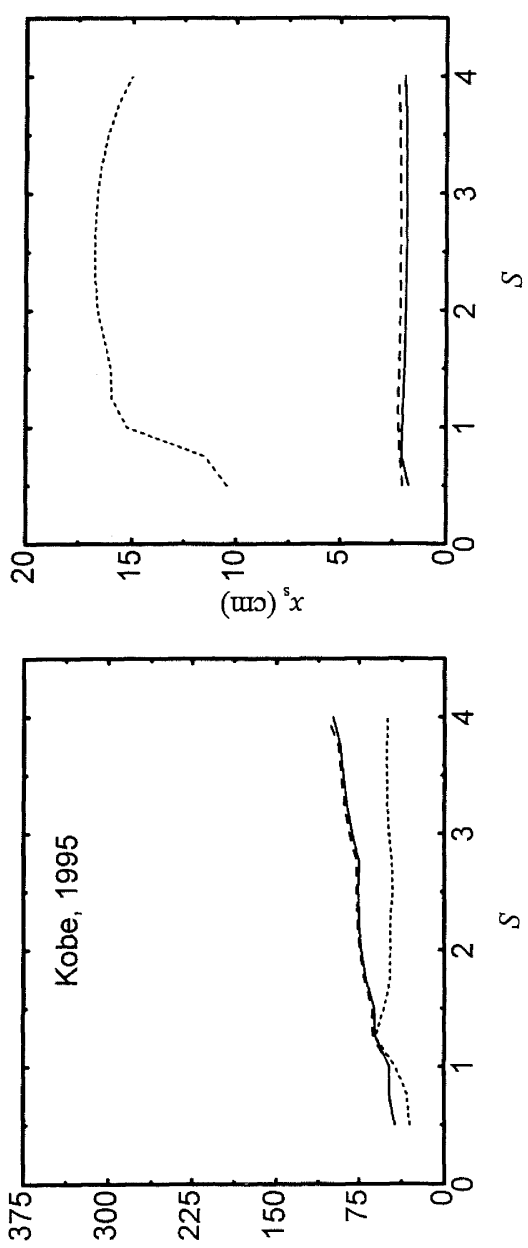

(س०) $)^{2} x$ 

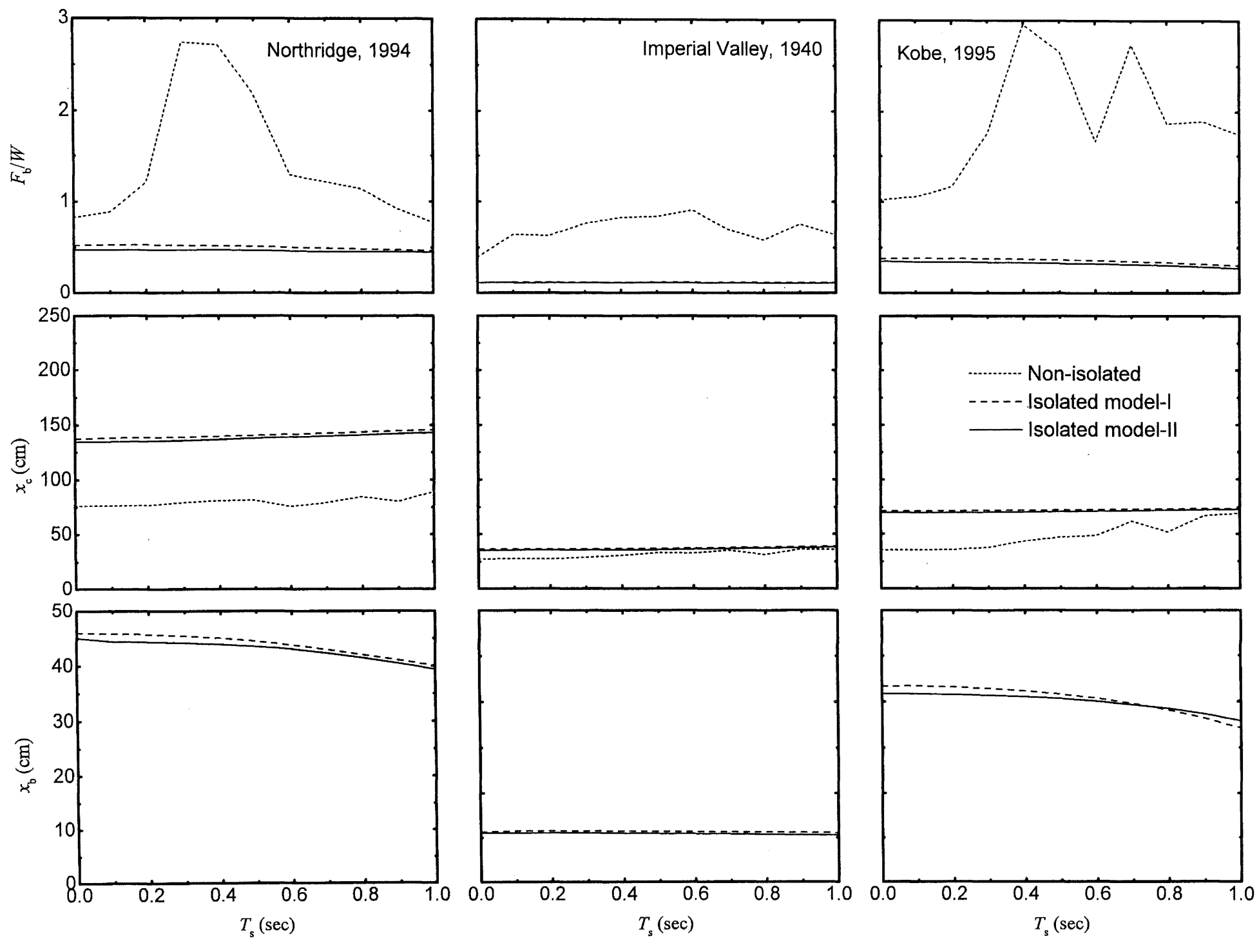

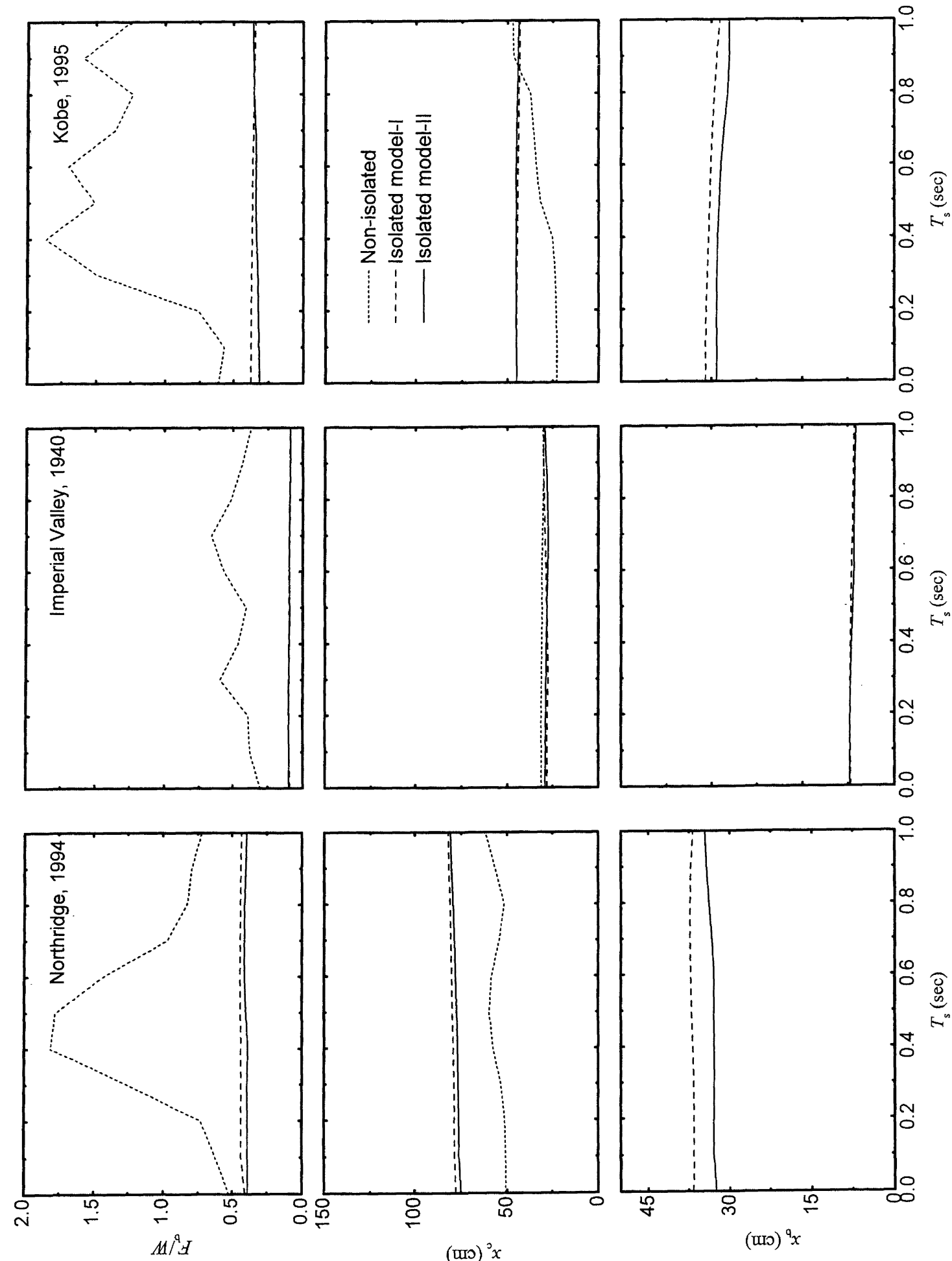

Figure 7. Effects of time period of tower structure on the seismic response of broad tank $\left(T_{b}=2 \mathrm{sec}, \xi_{b}=0.05\right.$ and $\left.F_{0}=0.05\right)$ 

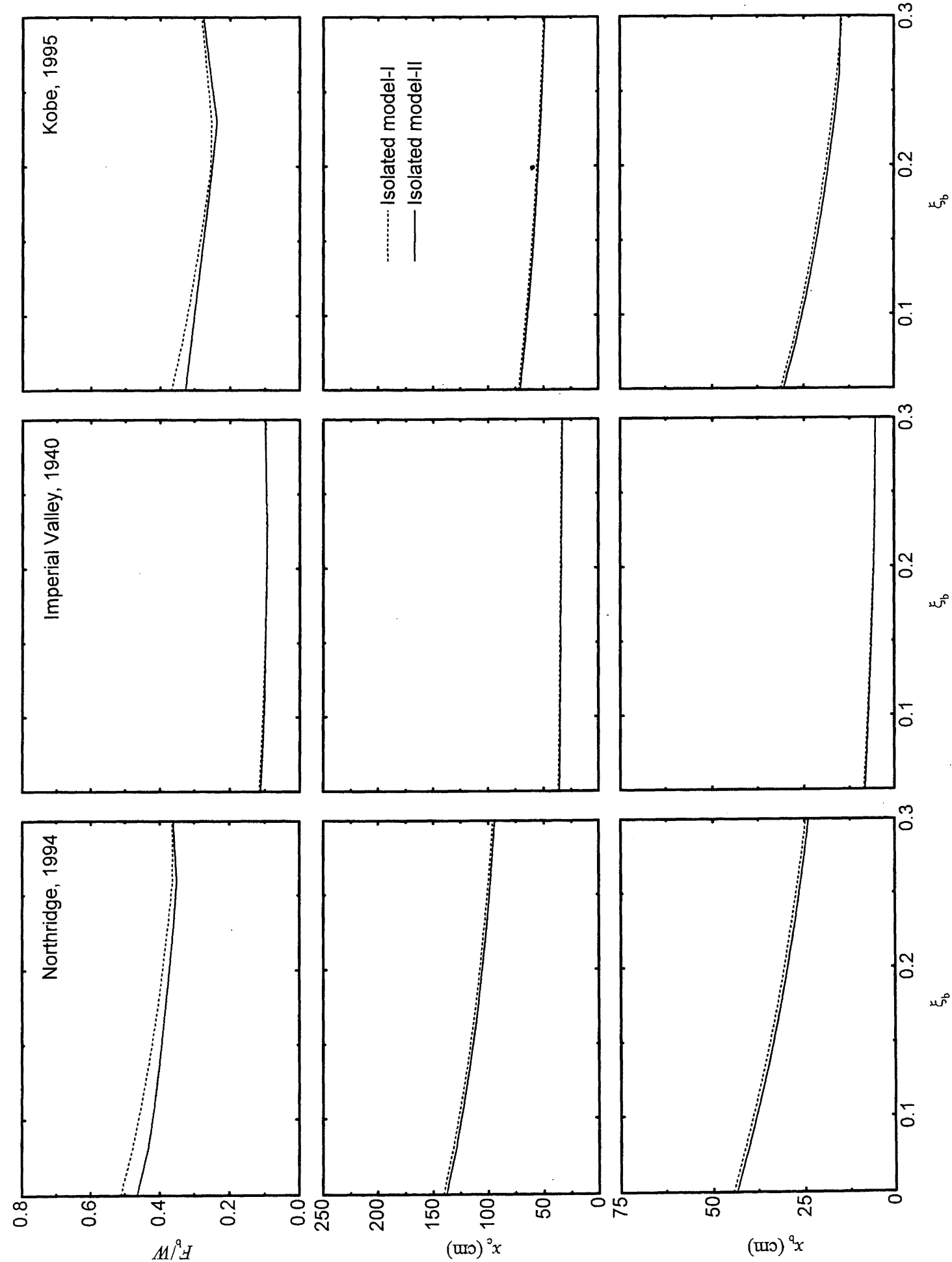

Figure 8. Effects of isolation damping on the seismic response of slender tank $\left(T_{b}=2 \mathrm{sec}, T_{s}=0.5 \mathrm{sec}\right.$ and $\left.F_{0}=0.05\right)$. 

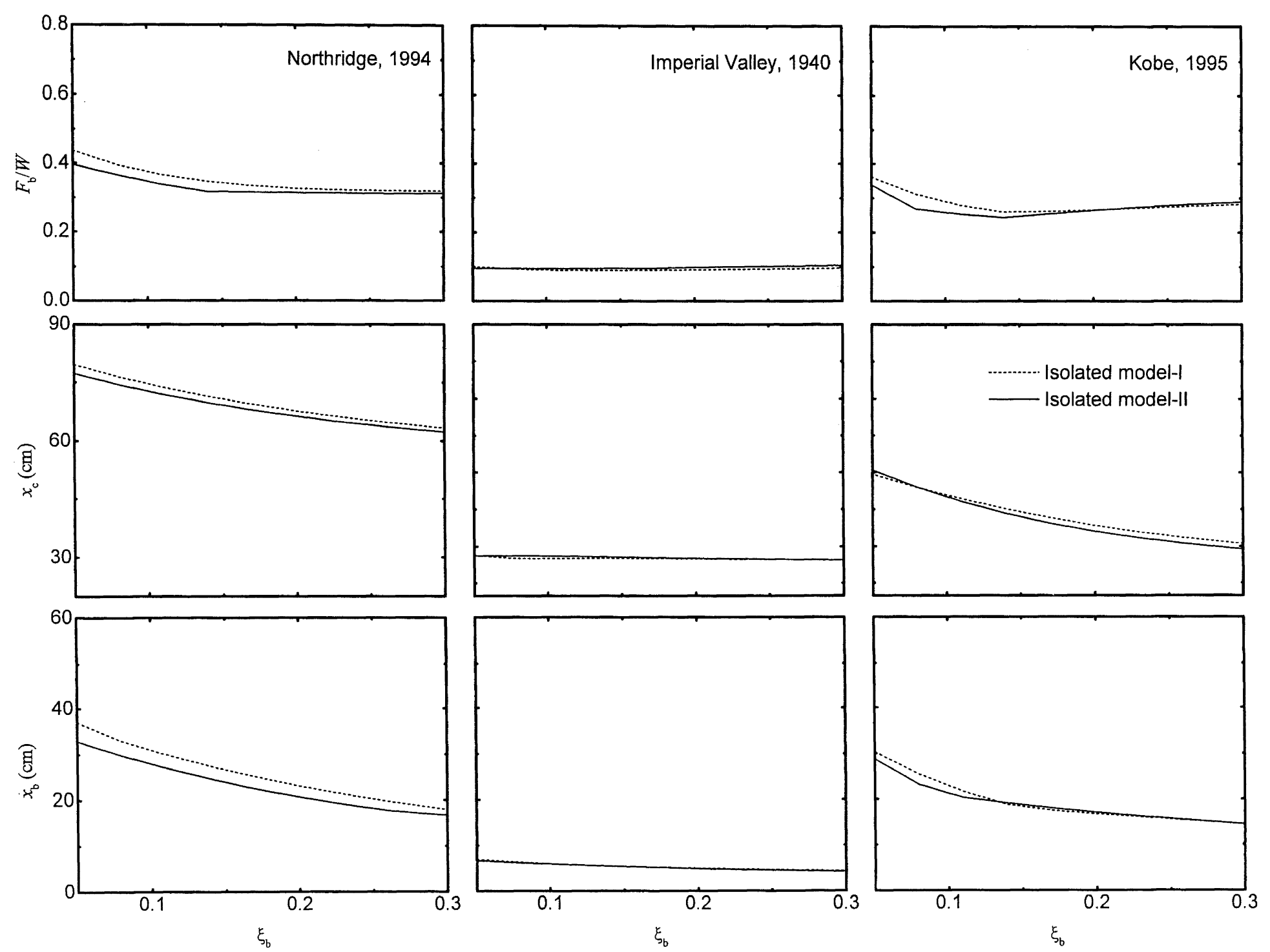

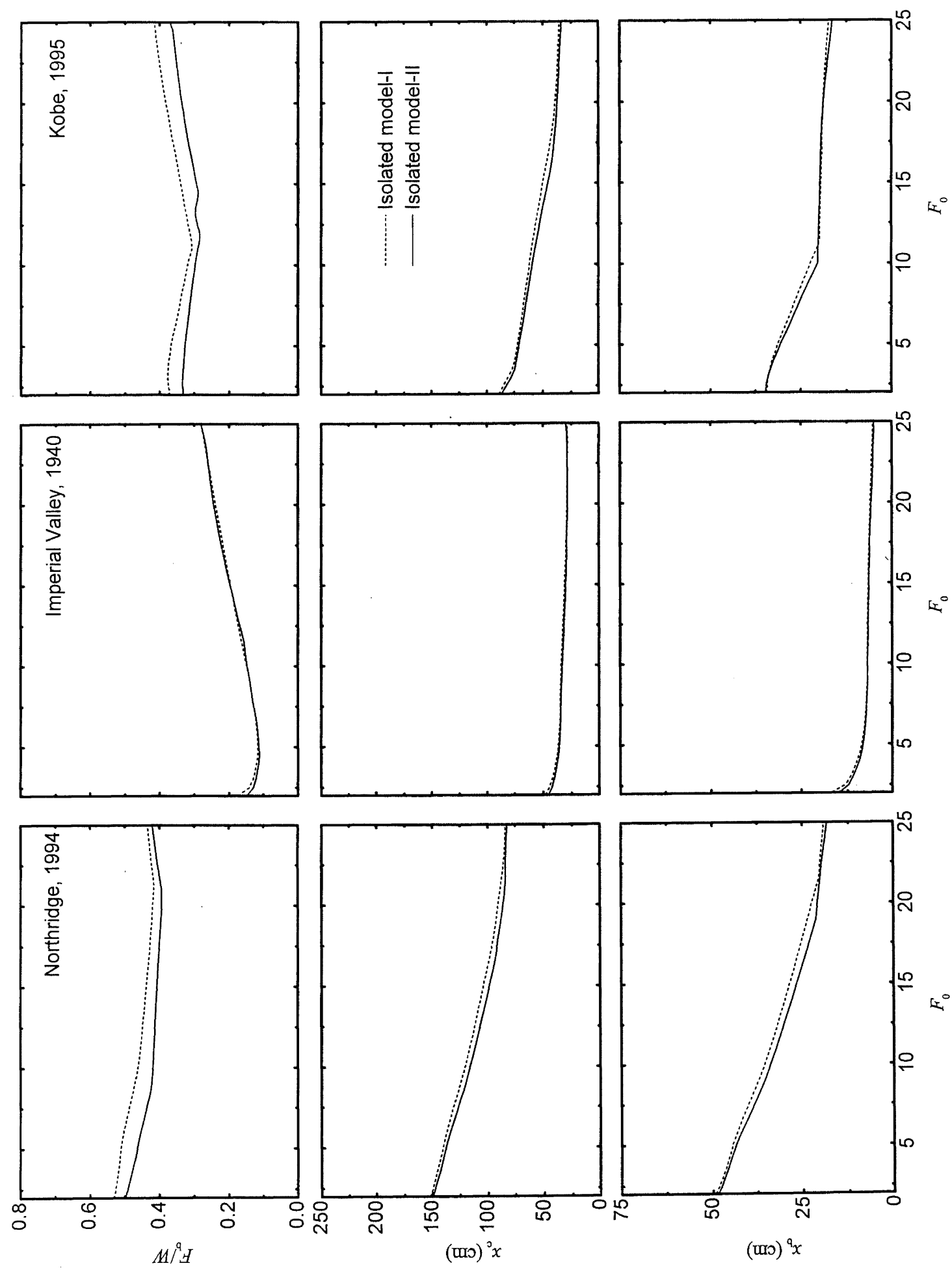

Figure 10. Effects of yield strength of isolation system on the seismic response of slender tank $\left(T_{b}=2 \mathrm{sec}, T_{s}=0.5 \mathrm{sec}\right.$ and $\xi_{b}=$ 0.05). 

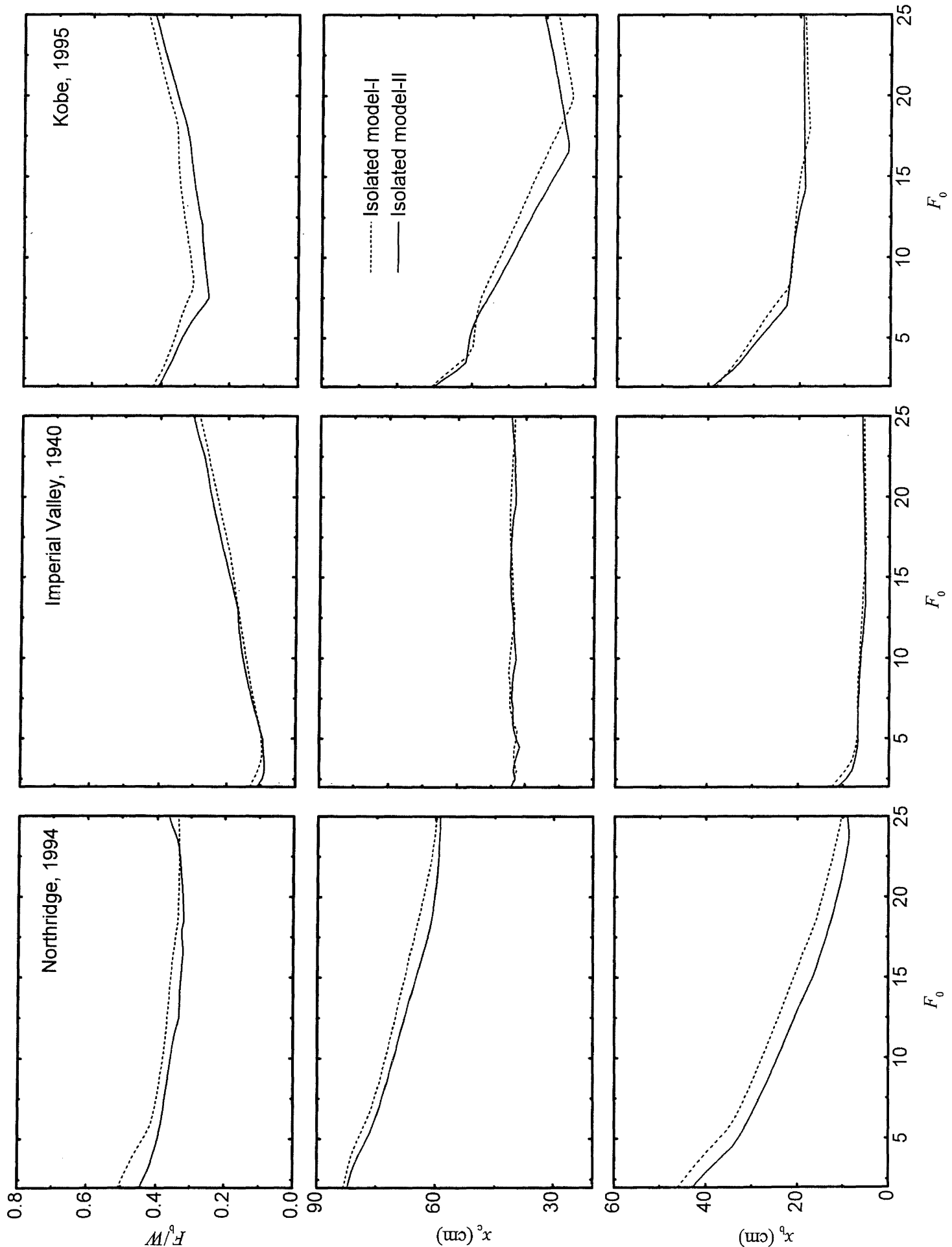

Figure 11. Effects of yield strength of isolation system on the seismic response of broad tank $\left(T_{b}=2 \mathrm{sec}, T_{s}=0.5 \mathrm{sec}\right.$ and $\xi_{b}=$ 0.05). 

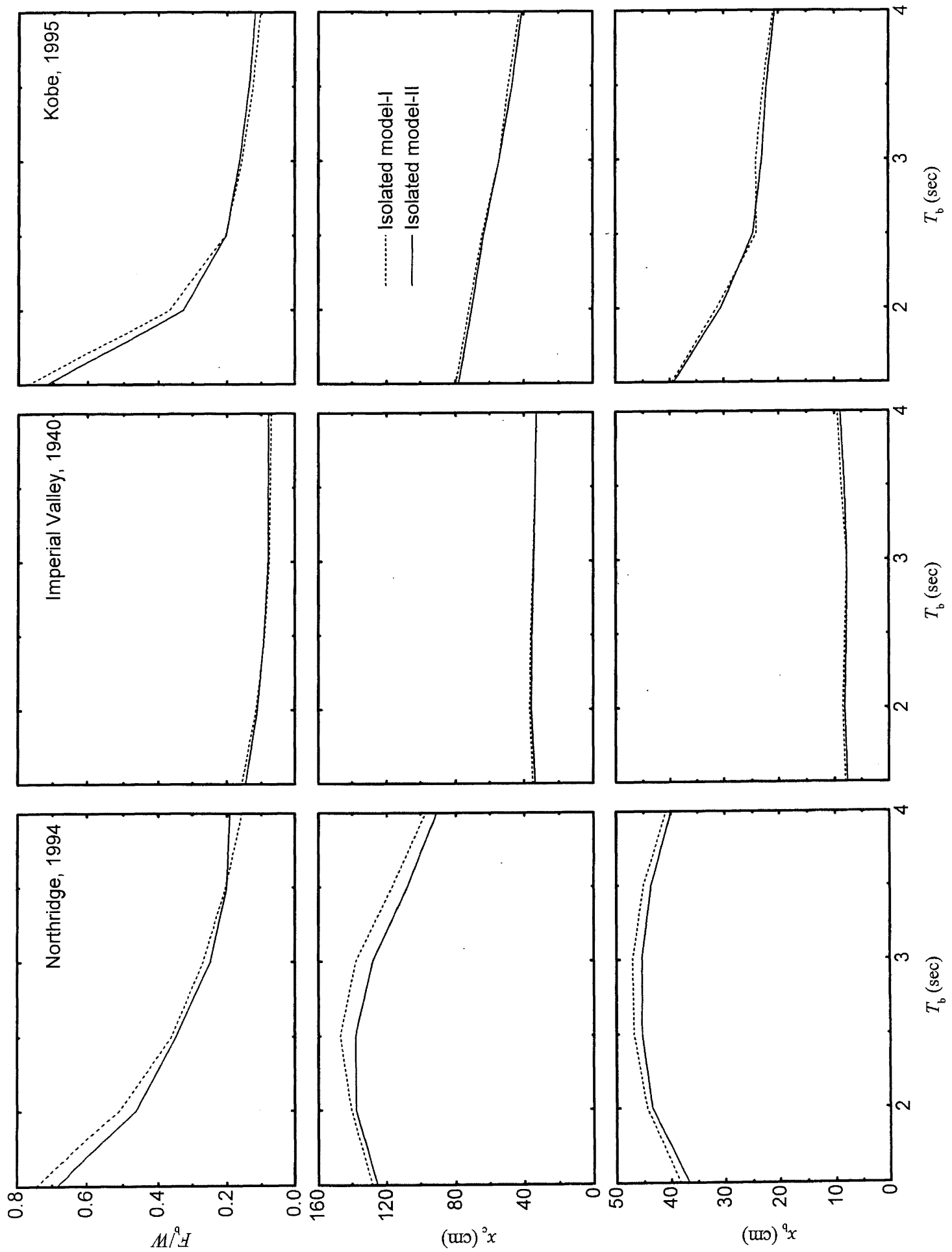

Figure 12. Effects of isolation time period on the seismic response of slender tank $\left(\xi_{b}=0.05, T_{s}=0.5 \sec\right.$ and $\left.F_{0}=0.05\right)$. 

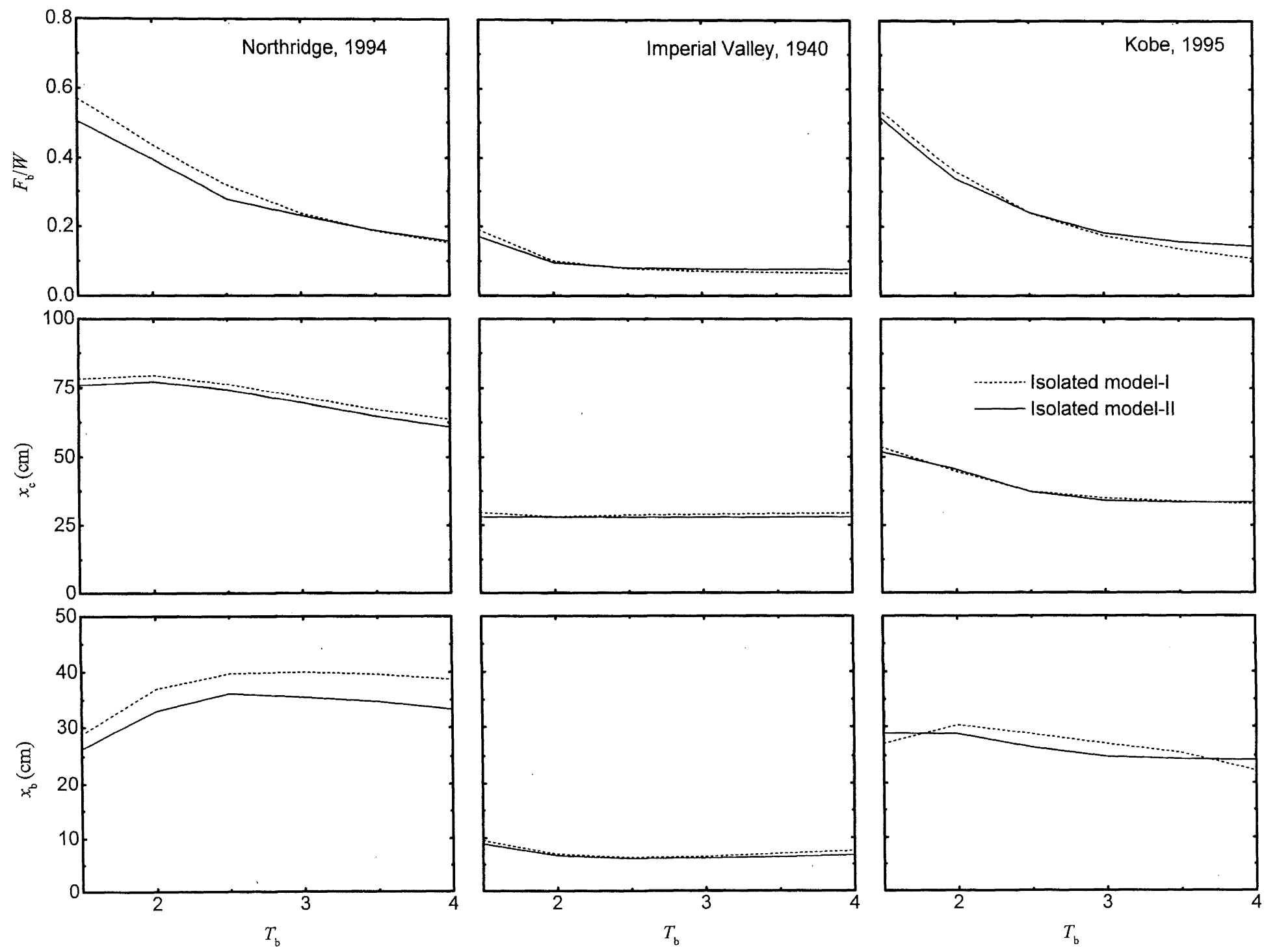


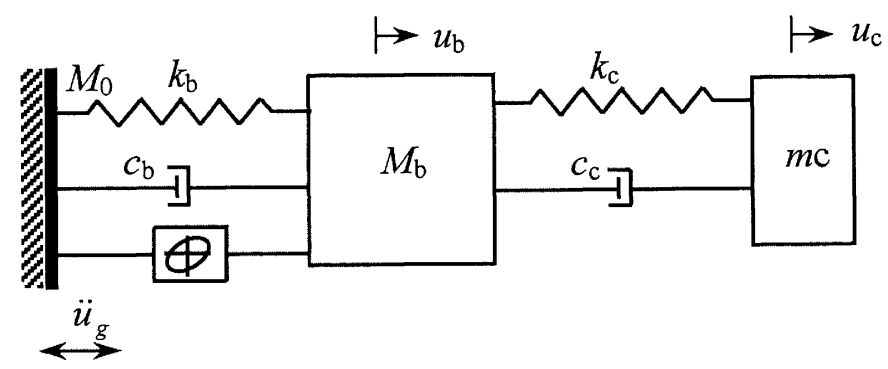

(a) Coupled Model
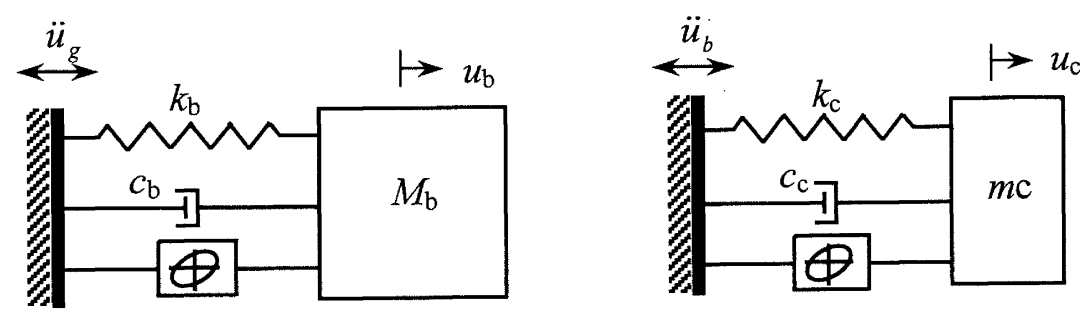

(b) Decoupled Model

Figure 14. Simplified model of isolated elevated liquid storage tanks (a) coupled model and (b) decoupled model.

The earthquake response of elevated liquid storage steel tanks was investigated using decoupled and coupled analyses with two-degrees-of-freedom system, which are associated with sloshing mass and bearing displacements. The two tank models considered for this analysis were based upon the reduced model of isolated model-I and isolated model-II. The reduced model of elevated liquid storage tank was used to investigate the response using decoupled and coupled analysis. The equivalent parameters such as stiffness and damping for sloshing mass, $\left(k_{\mathrm{c}}, c_{\mathrm{c}}\right)$ and the isolation system, $\left(k_{\mathrm{h}}, c_{\mathrm{h}}\right)$ are computed based on simple single-degree-offreedom system. The mass $M_{\mathrm{b}}$ mentioned in the Figure 14 for the model-I is equal to $m_{\mathrm{c}}+m_{\mathrm{i}}+3 m_{\mathrm{b}}$ while for the model-II it is $m_{\mathrm{c}}+m_{\mathrm{i}}$. The mass $M_{0}$ lumped at the foundation level for the model-I is equal to $2 m_{\mathrm{b}}$ and is null for modal-II. For the decoupled model analysis the sloshing mass was subjected to improved acceleration (i.e. $\ddot{u}_{b}=\ddot{x}_{b}+\ddot{u}_{g}$ ) for accurate estimation of the response. In order to verify the accuracy of the response obtained by decoupled analysis the response was compared with the corresponding response predicted by coupled analysis and exact response (i.e. obtained by the four-degrees-of-freedom models, refer Figure 1(b) and 1(c)).
Figures 15 and 16 show the variation of peak response obtained by decoupled and coupled analyses for reduced isolated model-I and isolated model-II, respectively. It was observed that the coupled and exact analysis predicted the identical result closely because the period of the tower structure does not significantly influence the response of isolated tanks (refer Figure 5). Further, the figures also indicate that the decoupled analysis predicts the conservative estimate of the response. This is because there is weak coupling between the sloshing frequency and isolation frequency specifically at lower aspect ratios but at higher aspect ratios there is strong coupling between the sloshing mass and isolation system. Therefore, the difference between the response predicted by the decoupled analysis and coupled analysis is relatively more at higher aspect ratios in comparison lower aspect ratios. The bearing and sloshing displacements obtained by the decoupled analysis for both the models were slightly higher for broad tanks while for slender tanks the difference further increases. The base shear obtained by the decoupled analysis gives marginally higher results in comparison to coupled analysis and the exact response which are close, since the contribution of sloshing to total base shear is negligible. These results indicate that the response of isolated elevated tanks can be predicted by decoupled analysis without losing accuracy. 

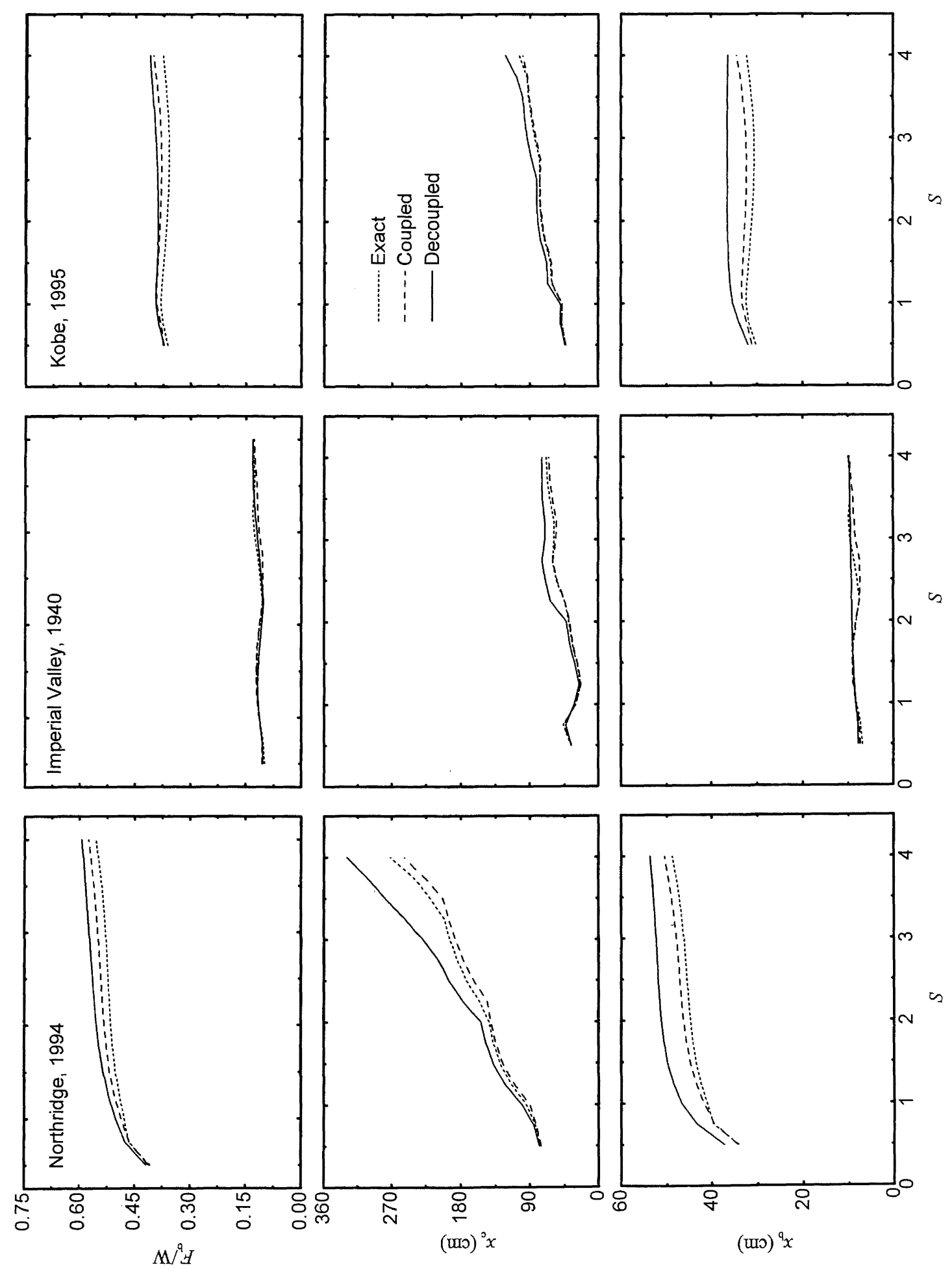

Figure 15. Variation of approximate and exact response of the isolated tank model-I against tank aspect ratio $\left(T_{b}=2\right.$ sec, $\xi_{b}=$ 0.05 and $F_{0}=0.05$ ). 

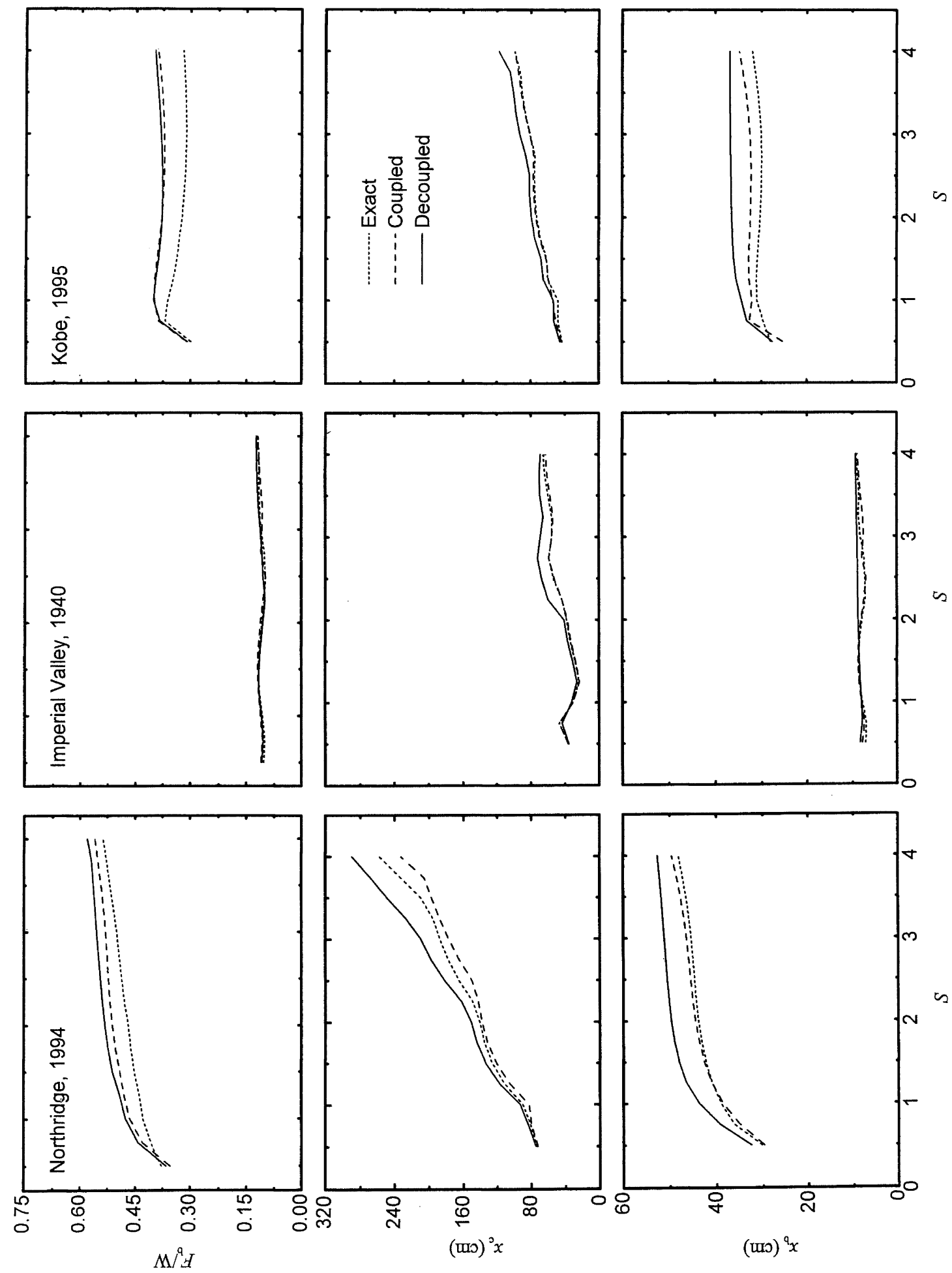

Figure 16. Variation of approximate and exact response of the isolated tank model-II against tank aspect ratio $\left(T_{b}=2\right.$ sec, $\xi_{b}=$ 0.05 and $F_{0}=0.05$ ). 


\section{CONCLUSIONS}

Comparative performance of elevated liquid storage tanks isolated by placing the lead-rubber bearings at top and bottom of the tower structure was investigated under recorded earthquakes. The seismic response of isolated tanks was compared with non-isolated tanks to measure the effectiveness of the isolation. In addition to this, a simplified decoupled analysis was carried out to investigate the response on the assumption that the motion of tower structure was rigid under earthquake excitation. The following conclusions are drawn from the study of isolated elevated liquid storage tank:

1. In general the two tank models predict similar response and provide the same effectiveness of base isolation

2. It was observed that the base shear was reduced significantly due to isolation the tanks. The base shear of the isolated tanks was mainly dominated by the impulsive and rigid mass components.

3. The tower drift was reduced significantly, due to isolation of the tanks. Further, the peak response of isolated tanks was insensitive to the flexibility of the tower structure.

4. The effectiveness of seismic isolation increases with the increase of bearing flexibility.

5. There exist an optimum value of bearing damping and yield strength at which the base shear is a minimum.

6. The simplified method accurately predicts the peak response of the isolated elevated liquid storage tank with significantly less computational efforts.

\section{REFERENCES}

1. Steinbrugge, K.V. and Rodrigo, F.A. (1963). The Chilean earthquakes of May 1960: A structural engineering viewpoint. Bulletin of Seismological Society of America, 53, 225-307.

2. Housner, G.W. (1963). Dynamic behavior of water tanks. Bulletin of Seismological Society of America, 53, 381387.

3. Rosenblueth, E. and Newmark, N.M. (1971) Fundamentals of Earthquake Engineering. Prience-Hall: NJ.

4. Epstein, H.I. (1976). Seismic design of liquid storage tanks. Journal of structural Division, ASCE, 102, 16591673.

5. Haroun, M.A. (1983). Vibration studies and test of liquid storage tanks. Earthquake Engineering and Structural Dynamics, 11, 179-206.
6. Kelly, J.M. (1986). Aseismic base isolation: Review and bibliography. Soil Dynamics and Earthquake Engineering, 5, 202-216.

7. Robinson, W.H. (1995). Recent research and application of seismic isolation in New Zealand. Bulletin of the New Zealand National Society for Earthquake Engineering, 28, 253-264.

8. Jangid, R.S. and Datta, T.K. (1995). Seismic behaviour of base-isolated buildings: A-state-of-the-art review. Journal of Structures and Buildings, ICE, 110(2), 186203.

9. Chalhoub, M.S. and Kelly, J.M. (1990). Shake table test of cylindrical water tanks in base-isolated structures. Journal of Engineering Mechanics, ASCE, 116(7), 14511472.

10. Kim, N.S., Lee, D.G. (1995). Pseudo-dynamic test for evaluation of seismic performance of base-isolated liquid storage tanks. Engineering Structures, 17(3), 198-208.

11. Malhotra, P.K. (1997). Method for seismic base isolation of liquid storage tanks. Journal of Structural Engineering, ASCE, 123(1), 113-116.

12. Malhotra, P.K. (1997). New methods for seismic isolation of liquid-storage tanks. Earthquake Engineering and Structural Dynamics, 26, 839-847.

13. Bleiman, D. and Kim S. (1993). Base isolation of high volume elevated water tanks. Proceeding, Seminar on seismic isolation, passive energy dissipation and active control, ATC 17-1, Applied Technology Council, Redwood city, California, USA.

14. Shenton, III H.W. and Hampton, F.P. (1997). Seismic response of isolated elevated water tanks. Journal of Structural Engineering, ASCE, 125(9), 965-976.

15. Robinson, W.H. and Tucker, A.G. (1977). A lead rubber shear damper. Bulletin of the New Zealand National Society for Earthquake Engineering, 10, 151-153.

16. Robinson, W.H. and Tucker, A.G. (1981). Test results for lead rubber bearings for Wm. Clayton Building, Toe Toe Bridge and Waiotukupuna Bridge. Bulletin of the New Zealand National Society for Earthquake Engineering, 14, 21-33.

17. Robinson, W.H. (1982). Lead rubber hysteretic bearing suitable for protecting structures during earthquakes. Earthquake Engineering and Structural Dynamics, 10 , 593-604.

18. Wen, Y.K. (1976). Method of random vibration of hysteretic system. Journal of Engineering Mechanics, ASCE, 102, 249-263. 